\title{
Estudio de patrones espaciales y de reconstrucción paisajistica mediante el uso de sistemas de información geográfica (Praileaitz I, Deba, Gipuzkoa)
}

\section{Eredu espazialak sortzea eta paisaiaren berreraikitzea geografia informazioko sistemen bitartez (Praileaitz I, Deba, Gipuzkoa)}

\author{
Study of spatial patterns and landscape reconstruction using geographic \\ information systems \\ (Praileaitz I, Deba, Gipuzkoa)
}

PALABRAS-CLAVE: Paleoacantilado, Ruta óptima, Transgresión marina, Tardiglaciar, Cambio climático. GAKO-HITZAK: Paleolabarra, Ibilbide hoberena, Itsas-transgresioa, Izoztaro berantiarra, Klima-aldaketa. KEYWORDS: Paleo sea-cliff, Optimal route, Marine transgression, Late glacial, Climate change.

\section{José Miguel EDESO-FITO(1), Jose Antonio MUJIKA-ALUSTIZA(2)}

\section{RESUMEN}

La profunda transformación experimentada por el medio durante el Pleistoceno Superior y, sobre todo, durante el Tardiglaciar y el Holoceno, supuso la drástica modificación de los ecosistemas existentes en la costa guipuzcoana, lo que sin duda incidió en los modos de vida (explotación de recursos, asentamientos...) de los diferentes grupos humanos que ocupaban el territorio considerado. Al margen de los importantes cambios climáticos acaecidos y de la consecuente transformación vegetal y faunística, la rápida elevación del nivel del mar (la línea de costa retrocedió más de 12 km en 11000 años) supuso el anegamiento de amplios espacios, obligando a los diversos grupos humanos a desarrollar nuevas estrategias de supervivencia.

No es descabellado suponer que dichos grupos humanos mantendrían algún tipo de contacto entre sí, por lo que se proponen diversas vías de desplazamiento obtenidas a partir de la modelización de la información en un Sistema de Información Geográfica (rutas óptimas).

\section{LABURPENA}

Goi Pleistozeno eta, bereziki, Izoztaro Berant eta Holozeno garaietan ingurumenean eraldaketa sakona gertatu zen. Ordura arte existitzen ziren ekosistemetan aldaketa zorrotzak ezagutu ziren, eta zalantzarik gabe aztertzen dugun lurraldean bizi ziren gizatalde ezberdinen bizimoduetan (baliabide ustiapenean, bizilekuetan...) eragina izan zuen. Gertatu ziren aldaketa klimatiko, eta ondorioz landaretzan eta faunan gertatukoez gain itsasmaila ere bizkor igo zen (itsas-lerroa 12 km atzeratu zen 11000 urtetan) lursail handiak urpetuz, eta bizi-irauteko estrategia berriak garatzera behartuz.

Ez da zentzugabea uste izatea talde horiek elkarren artean harremanak izango zituztela; horregatik Geografia Informazio Sistema (ibilbide ezin hobea) batean informazioa modelizatuz lortu diren desplazamendu bideak proposatzen dira.

\section{ABSTRACT}

The deep environmental change occurred during the Upper Pleistocene and, especially, during the Late Glacial and Holocene periods, entailed a drastic alteration of the existing ecosystems the same. In turn, these changes had an unquestionable impact on the lifestyle (exploitation of resources, settlements...) of the different human groups that lived in the territory under study. Beside the climatic changes and the consequent changes in flora and fauna, the rise in sea level (the shoreline retreated more than $12 \mathrm{~km}$ in 11000 years) meant the flooding of large spaces, which forced local human groups to develop new survival strategies.

It is not unreasonable to assume that these groups maintained some sort of contact with each other. To research this possibility we have analyzed the topographic surface of the area under study with the help of a Geographic Information System, using the optimal routes tool and as a result, possible different pathways between human settlements are proposed.

\footnotetext{
(1) Escuela Universitaria de Ingeniería (UPV-EHU). C/Nieves Cano 12. 01006 Vitoria-Gasteiz. Araba. josemiguel.edeso@ehu.es (2) Facultad de Letras (UPV-EHU). Tomás y Valiente $s / n$. Vitoria-Gasteiz.
} 
El presente trabajo se engloba dentro del estudio multidisciplinar realizado por diversos grupos de investigadores en la cavidad y en el entorno del yacimiento de Praileaitz I (Deba, Gipuzkoa). Esta cueva se enmarca en un contexto arqueológico rico en yacimientos, situados, la mayor parte de ellos en el tramo final del valle-estuario del río Deba. El conocimiento de los diversos ambientes y paisajes existentes durante el Pleistoceno Superior y el Holoceno puede aportar luz sobre los fenómenos naturales que, de alguna manera, condicionaban la viabilidad o no de los asentamientos humanos, así como las posibles rutas que dichos grupos podrían seguir en sus desplazamientos.

La cavidad se localiza en la orilla derecha del río Deba, a 50 msnm, en una ladera dominada por fuertes pendientes, estando su boca orientada al NE, justo por encima de los meandros encajados que caracterizan el tramo bajo (y el estuario) del río.

\section{1.- OBJETIVO Y MÉTODO}

El objetivo del presente trabajo es, por un lado, la reconstrucción paisajística del entorno de Praileaitz durante el Pleistoceno Superior y el Holoceno y, por otro, la modelización de las rutas o caminos óptimos teóricamente utilizados por los diversos grupos humanos que ocupaban la zona, efectuando para ello la modelización del territorio mediante las herramientas proporcionadas por los Sistemas de Información Geográfica.

En el primer caso, la caracterización de las condiciones del medio natural se ha efectuado a partir de la información proporcionada por los diversos investigadores que durante las últimas décadas han abordado diferentes aspectos relacionados con el clima, la vegetación y el territorio. La determinación del nivel del mar durante el período considerado, se ha realizado a partir de las propuestas de curvas de elevación efectuadas en distintos puntos del litoral cantábrico para el Holoceno y del estudio de los pulsos transgresivos acaecidos durante el Pleistoceno en distintos lugares del globo.

La modelización del fondo marino (hasta los -100 m) se ha elaborado a partir de las isobatas elaboradas por AZTI Tecnalia. Esta información se ha descargado desde la página del Gobierno Vasco, procediéndose posteriormente a su implementación en un SIG y a la generación del MDT mediante el uso del algoritmo de interpolación IDW.

\section{2.- EL MEDIO DURANTE EL PLEISTOCENO SU- PERIOR EN EL ENTORNO DE PRAILEAITZ I}

En las últimas décadas hemos asistido a una auténtica revolución científica, tanto en lo que se refiere a las técnicas de datación (AMS, U/Th, TIMS...), como en lo relativo al desarrollo de diversas metodologías y disciplinas cuyos esfuerzos se centran en la reconstrucción paleoambiental (sedimentología, palinología, paleoclimatología, antracología, análisis isotópico de los núcleos de hielo, análisis isotópico de foraminíferos, etc.) del Cuaternario. Todos estos esfuerzos han permitido elaborar una serie de curvas paleoclimáticas de gran precisión ambiental y cronológica, así como reconstruir las cubiertas vegetales existentes a lo largo del Pleistoceno y Holoceno.

El Cuaternario, que se inició hace 2588 millones de años, se divide en 106 estadios isotópicos (MIS) numerados del 106 al 1. Los números impares (excepto el 3 identificado erróneamente con un período templado) se vinculan con fases cálidas, mientras que los pares se relacionan con períodos fríos. El Pleistoceno Superior se extiende entre los estadios isotópicos 5 y 2 (0,13 a 0,011 ka), englobando el interglaciar Riss-Würm (Eemiense) y la glaciación Wurmiense, mientras que el Holoceno o período interglaciar actual, se corresponde con el estadio isotópico 1 y no es sino el último interglaciar acaecido, en el que actualmente nos encontramos (URIARTE, 2003; LISIECKI et al., 2005).

\subsection{Rasgos morfotopográficos continentales}

El yacimiento arqueológico de Praileaitz I se localiza en el tramo inferior del valle del Deba (orilla derecha), muy cerca ya del estuario del mismo nombre. El entorno presenta una morfología bastante abrupta y escarpada, que refleja fielmente las diferencias litológicas que existen entre el sector septentrional y el meridional (Fig. 1). En el primer caso predominan las litologías "blandas", pudiendo destacar, entre otras, los materiales de la formación Sasiola (alternancia de calizas, calcarenitas, margas y brechas calcáreas), el Flysch negro, las areniscas de Istiña y las margas de Itziar. El paisaje resultante está dominado por una serie de colinas de cima plana o suavemente redondeada, separadas entre sí por valles en $\mathrm{V}$ más o menos amplios. Al alcanzar la línea de costa estos materiales han sido fácilmente erosionados por la acción de las olas y corrientes marinas, lo que explica la formación de un importante acantilado vertical (20 a 30 m de altura) a cuyos pies se desarrolla una amplia plataforma de abrasión marina. Este muro continuo tan sólo se ve interrumpido por los estuarios del Urola y del Deba.

El sector meridional presenta una morfología mucho más agreste y escarpada ya que coincide con los relieves carbonatados (calizas arrecifales y pararrecifales urgonianas) que articulan la alineación Erlo-Anduz-Arno. Se define como un paisaje de media montaña, profundamente karstificado e intensamente descarnado. Morfológicamente se resuelve mediante una sucesión de crestas y crestones calizos, entre las que se desarrollan todo un cortejo de formas exo y endokársticas, pudiendo citar por su importancia el valle seco de Lastur (de dirección general NW-SE), la depresión de Astigarribia, la depresión de Olatz y el valle kárstico de Ugarteberri. En este ámbito son particularmente abundantes las doli- 


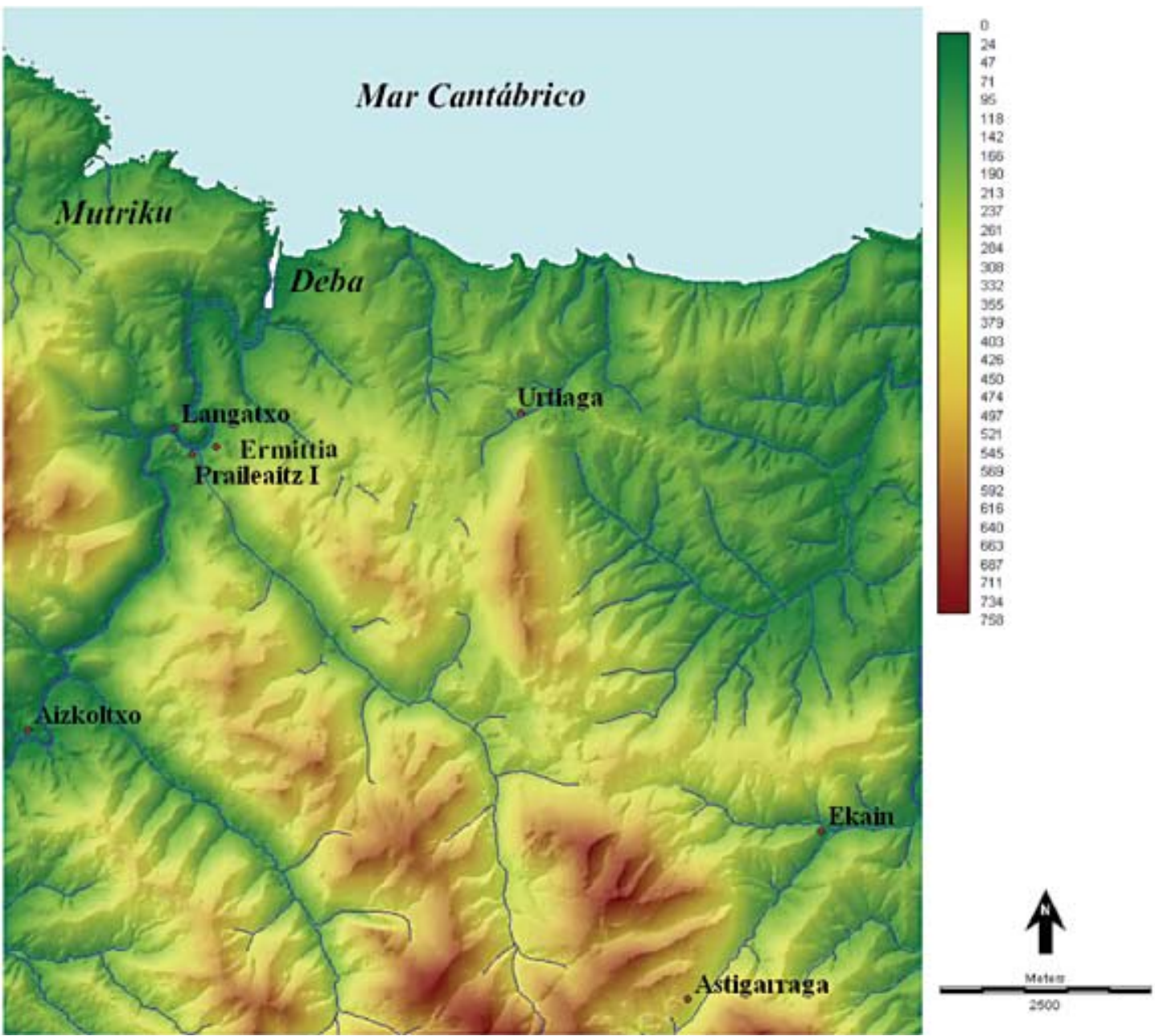

Fig. 1. Localización de los principales yacimientos prehistóricos existentes en la zona de Deba. / Distribution of the main prehistoric sites in the area of Deba.

nas, los lapiaces, los sumideros y, como no podía ser de otra forma, las cavidades. Estos relieves, al ser incididos por la red hidrográfica del Deba, dan lugar a angostos valles en $\mathrm{V}$ dominados por fuertes pendientes verticales y/o subverticales. En ocasiones los ríos se ven obligados a dibujar una serie de meandros encajados para poder alcanzar la línea de costa. Es en uno de estos meandros donde se localizan las cavidades de Iruroin, Langatxo, Ermittia y Praileaitz I y II.

Si analizamos la tabla 1, advertimos que los valores de pendiente son muy elevados en la zona de estudio, hasta tal punto que el $66,09 \%$ del territorio presenta pendientes por encima del 30\% (el 32,51\% supera el 50\%), de ahí que el valor medio de la zona oscile en torno al $41,98 \%$. Advertimos también que el sector septentrional presenta valores más bajos que el meridional, lo que refleja la desigual dureza de los materiales que integran una y otra zona, hecho que sin duda tuvo que condicionar los desplazamientos de los grupos humanos, e incluso los asentamientos, ya que todas las cavidades conocidas se localizan cerca de los fondos de valle y en zonas, por lo general bajas.

\begin{tabular}{|c|c|c|}
\hline \multicolumn{3}{|c|}{ DISTRIBUCIÓN DE LAS PENDIENTES EN LA } \\
ZONA DE ESTUDIO \\
\hline Pendiente en \% & $\begin{array}{c}\text { Superficie en } \\
\text { hectáreas }\end{array}$ & $\%$ sobre el total \\
\hline$<2$ & 186,4 & 0,99 \\
\hline $2-5$ & 249,3 & 1,33 \\
\hline $5-10$ & 618,0 & 3,29 \\
\hline $10-20$ & 2277,3 & 12,13 \\
\hline $20-30$ & 3036,1 & 16,17 \\
\hline $30-40$ & 3255,6 & 17,33 \\
\hline $40-50$ & 3051,3 & 16,25 \\
\hline $50-100$ & 5782,8 & 30,79 \\
\hline$>100$ & 323,0 & 1,72 \\
\hline Total & 18779,8 & 100 \\
\hline
\end{tabular}

Tabl. 1. Distribución de las pendientes por intervalos. / Distribution of the slopes by interval. 
Fig. 2. Mapa de pendientes de la plataforma continental hasta los $100 \mathrm{~m}$ de profundidad (zona de Deba). / Slope map of the continental shelf down to $100 \mathrm{~m}$ deep (Deba area).

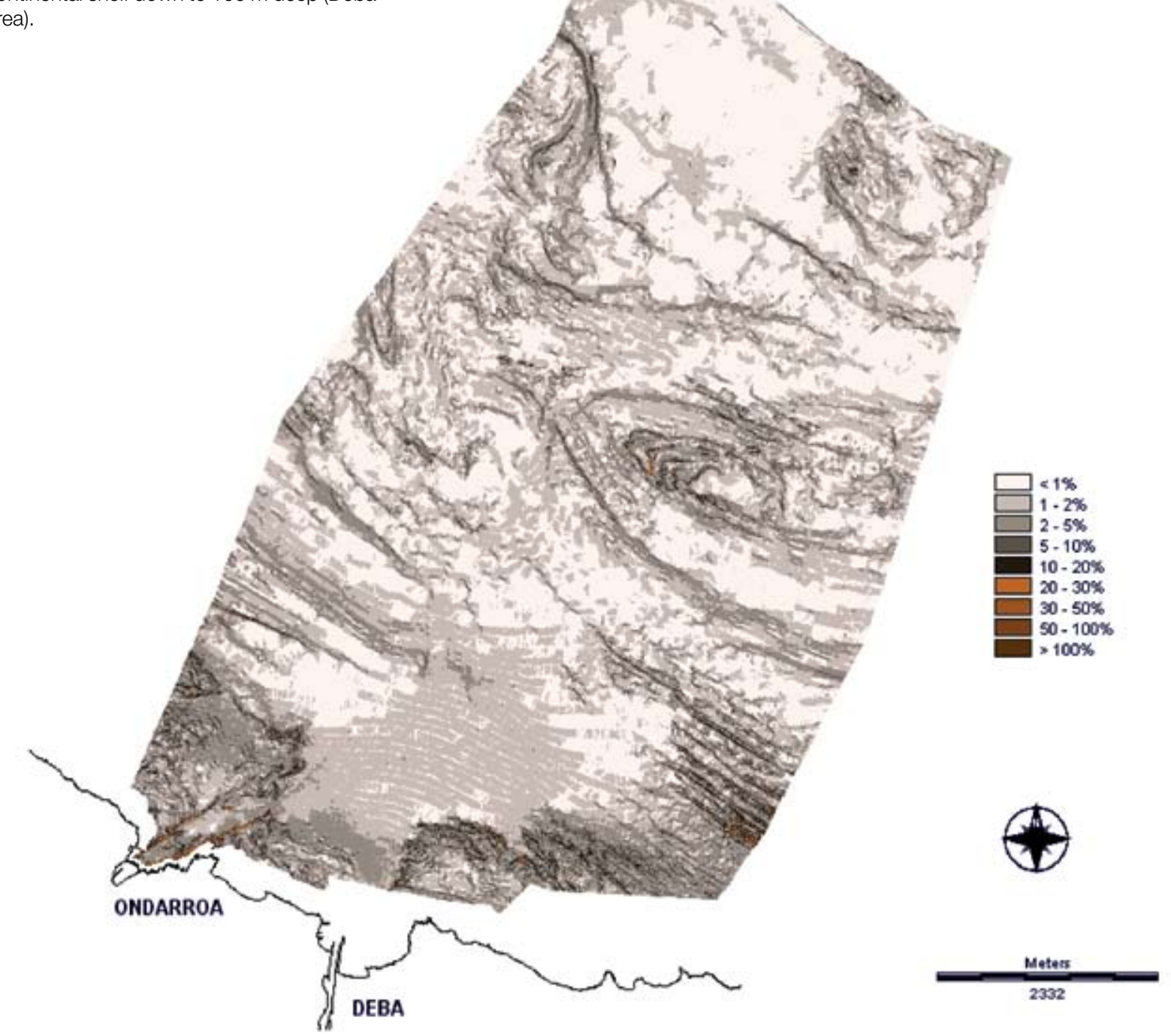

\subsection{Características morfotopográficas de la plataforma continental}

La plataforma continental actual tiene una pendiente media del 2\%, oscilando entre el 0 y el 129,9\% (Fig. 2 y Tabl. 2). Las zonas más escarpadas se localizan cerca de la costa, pudiendo destacar la depresión de Artibai (Figs. 3 y 4), cuyas paredes se disponen prácticamente verticales (sobre todo la ladera occidental), los relieves que configuran el sector oriental y que no son sino la prolongación submarina de las morfologías litorales y algunas estructuras y formas que aparecen entre los -60 y los -80 metros de profundidad (supuesto cierre periclinal y algunas bruscas rupturas de pendiente que hemos interpretado como paleoacantilados).

El análisis de la tabla adjunta pone de manifiesto que el $89,5 \%$ de la superficie estudiada presenta una pen- diente media inferior al 5\%, elevándose esta cifra hasta el $97,8 \%$ si consideramos los valores por debajo del 10\%. Tal y como hemos señalado anteriormente, las mayores pendientes se localizan en las zonas más próximas a la costa, ya que aquí los relieves litorales se sumergen rápidamente alcanzándose los 40 metros de profundidad en poco más de 1000 m. Únicamente coincidiendo con la desembocadura del Deba se observa una significativa disminución de la pendiente, lo que parece relacionarse con el antiguo paleovalle del río, hoy totalmente colmatado por sedimentos.

Una segunda zona escarpada se localiza entre los -60 y los $-70 \mathrm{~m}$ de profundidad. En este punto se observa una estructura alargada de dirección general E-O (Figs. 5 y 6) que se cierra por su extremo occidental dibujando un semicírculo que recuerda a los cierres peri- 


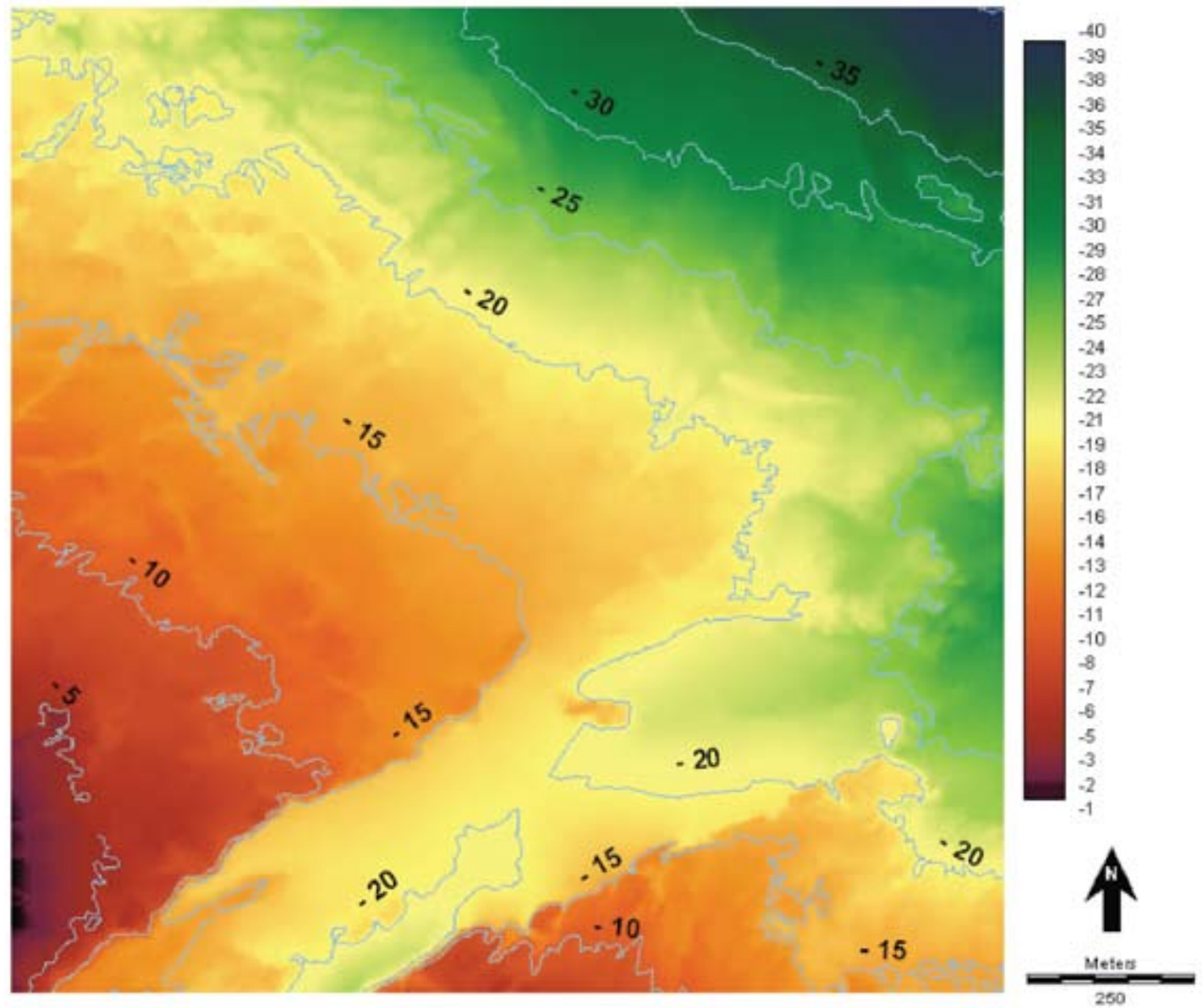

Fig. 3. Detalle de la depresión de Artibai. / Detail of the Artibai depression.

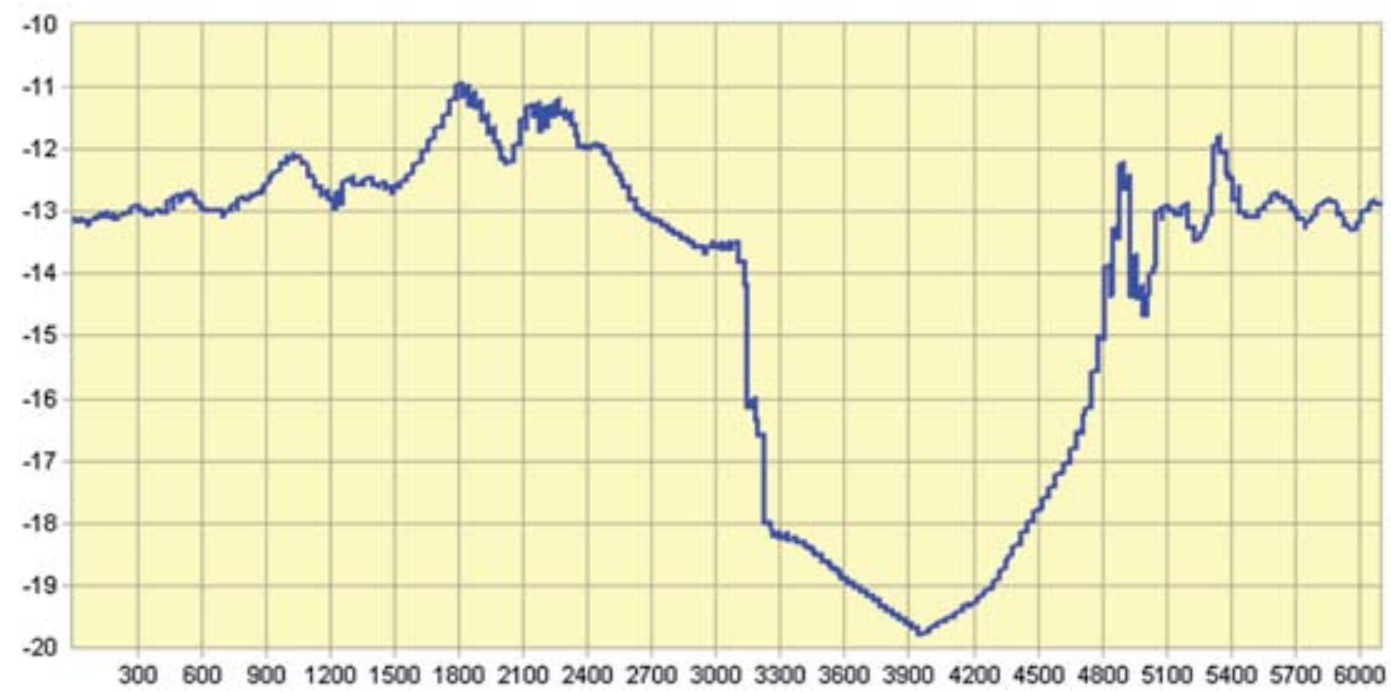

Fig. 4. Perfil de la depresión de Artibai (en metros). / Cross-section (transversal profile) of the Artibai depression. 


\begin{tabular}{|c|c|c|c|}
\hline \multicolumn{4}{|c|}{ VALORES DE PENDIENTE DE LA PLATAFORMA CONTINENTAL } \\
\hline $\begin{array}{c}\text { Pendiente } \\
\%\end{array}$ & $\begin{array}{c}\text { Superficie } \\
\text { Ha }\end{array}$ & $\begin{array}{c}\text { Porcentaje } \\
\%\end{array}$ & $\begin{array}{c}\text { Porcentaje acumulado } \\
\text { en } \%\end{array}$ \\
\hline$<1$ & 7862,3 & 57,5 & 57,5 \\
\hline $1-2$ & 2255,9 & 16,5 & 73,5 \\
\hline $2-5$ & 2114,3 & 15,5 & 89,4 \\
\hline $5-10$ & 1142,7 & 8,4 & 97,8 \\
\hline $10-20$ & 232,3 & 1,7 & 99,5 \\
\hline $20-30$ & 59,4 & 0,4 & 99,9 \\
\hline $30-50$ & 6,2 & 0,05 & 99,9 \\
\hline $50-100$ & 2,4 & 0,02 & 100 \\
\hline$>100$ & $<0,1$ & Inapreciable & 100 \\
\hline Total & 13675,3 & 100,0 & 100 \\
\hline
\end{tabular}

Tabl. 2. Distribución de las pendientes en la plataforma continental. / Distribution of the slopes on the continental shelf.

clinales. Un análisis más detallado de su morfología (Fig. 5), pone de manifiesto la presencia de numerosas depresiones cerradas (algunas de ellas de gran tamaño) que tienden a adoptar una orientación E-O y/o NO-SE. Junto a ellas encontramos pequeños escarpes rocosos alargados, relieves residuales y bruscas rupturas de pendiente que, o bien se relacionan con accidentes estructurales (fallas) o con antiguos acantilados. Varias rupturas muy nítidas se detectan entre los -68 y los $-63 \mathrm{~m}$ y entre los -59 y los $-55 \mathrm{~m}$ de profundidad.

En definitiva se trata de un pliegue constituido por materiales carbonatados sobre los que se desarrollaron diversas depresiones kársticas (dolinas) y, presumiblemente, cuevas y cavidades.
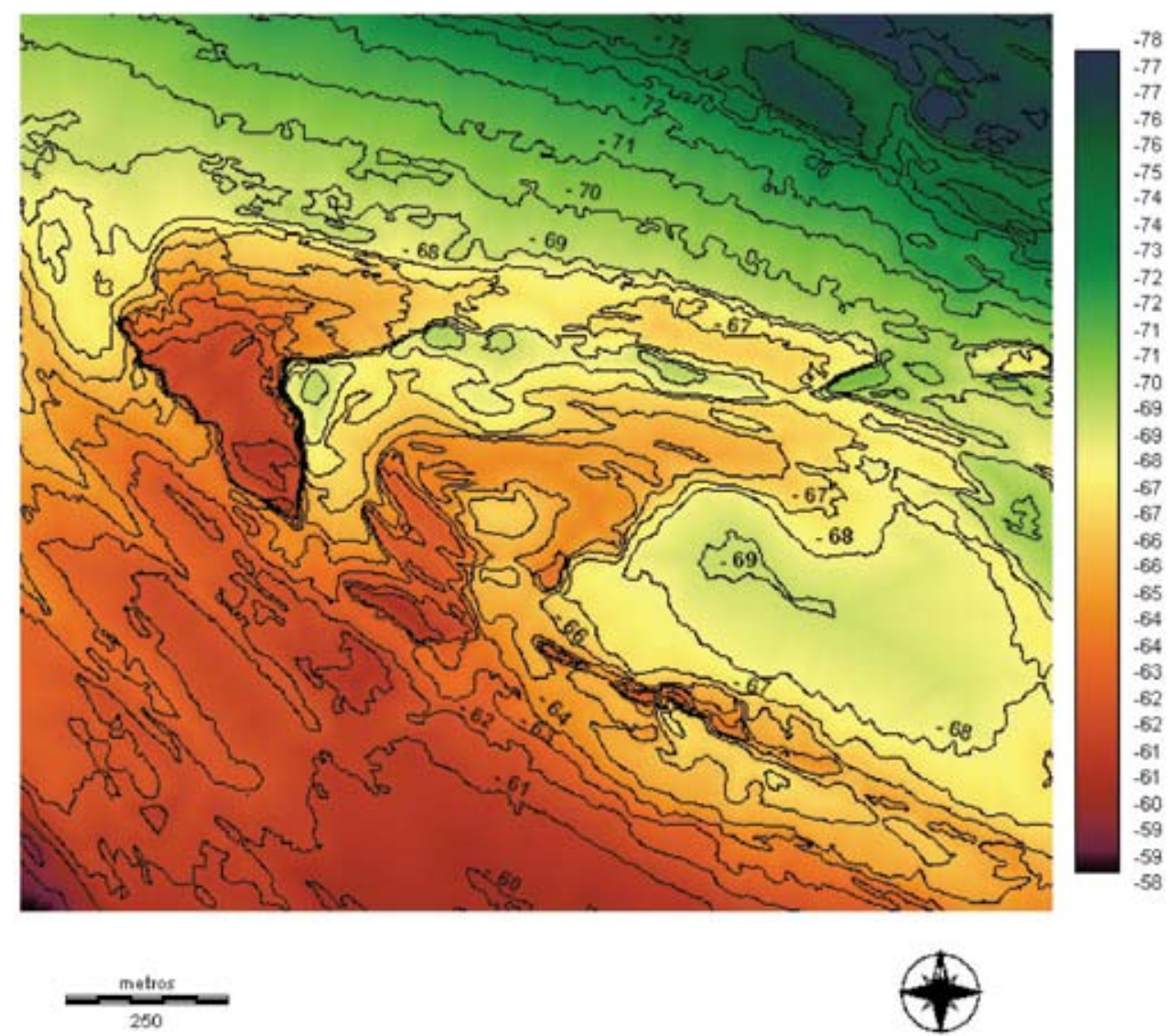

Fig. 5. Detalle del supuesto pliegue periclinal. / Detail of the hypothetical periclinal fold. 


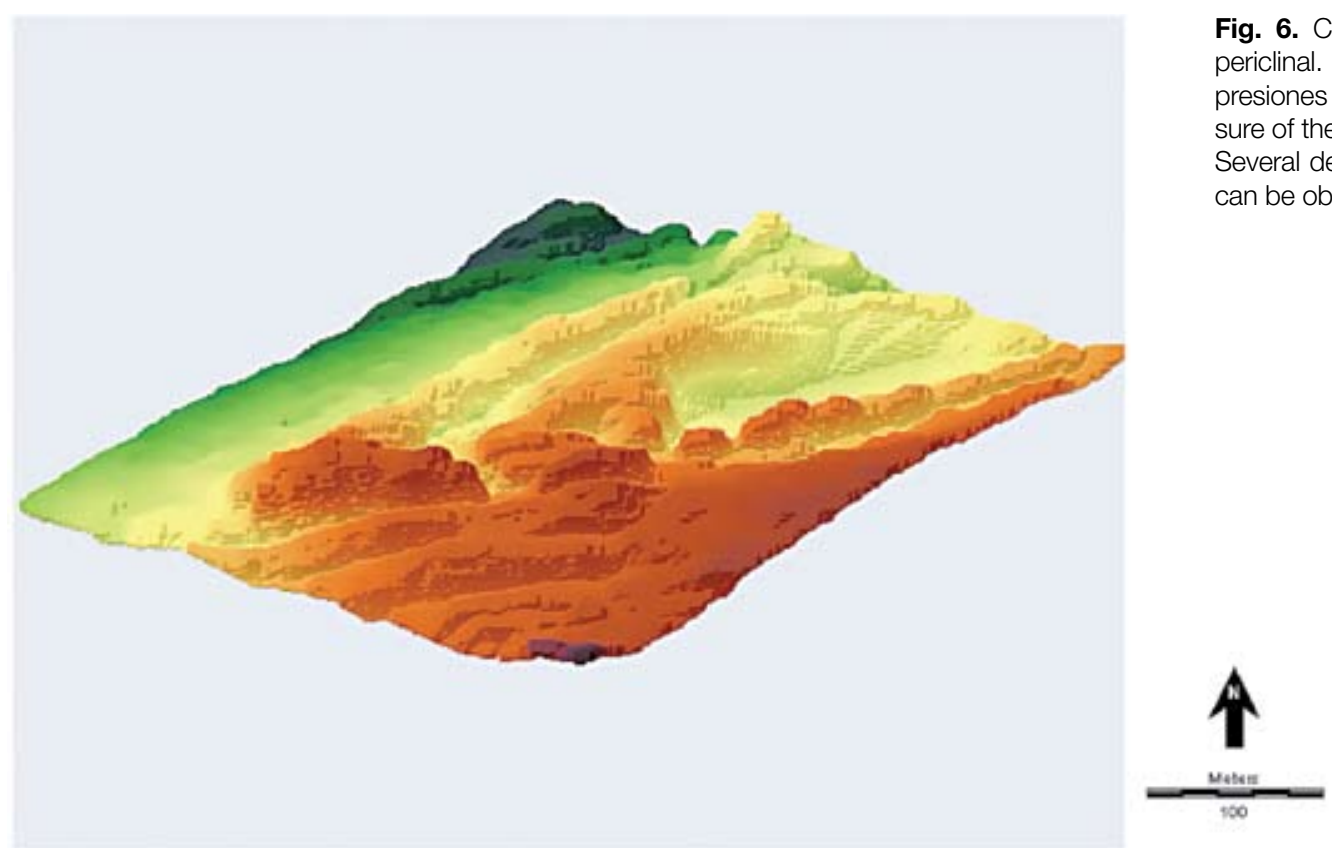

\subsection{El clima durante el Pleistoceno Superior}

El Pleistoceno Superior se inicia hace 128000 años (Interglaciar Riss-Würm o Terminación II), pudiendo subdividirse en dos períodos distintos, que son el Eemiense o estadio isotópico 5 y el Würmiense, que engloba los estadios isotópicos 4, 3 y 2. El primero se extiende entre los 128000 y los 74000 años, pero no es un período homogéneo ya que dentro de él se reconocen 5 subestadios isotópicos, de los que 3 son cálidos (5e, 5c, 5a) y 2 fríos (5d, 5b).

Entre el 74000 y el 11000 (estadios isotópicos 4 , 3 y 2) tiene lugar el Ciclo Glaciar Würmiense, el cual tampoco es homogéneo ya que se ve interrumpido por numerosos interestadiales. Inicialmente, entre el 74000 y el 59000 BP predominan las condiciones frías, lo que provocó una brusca disminución del nivel del mar. El estadio isotópico 3 (59000-28000 BP) es aún más frío, aunque se vio interrumpido por una serie de interestadiales más o menos templados, cuya duración oscila entre unos cientos y varios miles de años, destacando el acaecido a finales del Estadio Isotópico 4 y comienzos del 3, el de Hengelo (MENÉNDEZ et al., 1997) o el de Arcy-Denekamp.

A medida que nos aproximamos a los tiempos presentes la información disponible se diversifica y enriquece, ya que los vestigios existentes son cada vez más abundantes y se han conservado mejor. Mención especial merecen las curvas paleoclimáticas elaboradas a partir de los sondeos GISP2 y GRIP efectuados en Groenlandia. Dichas curvas nos permiten señalar que dentro del Estadio Isotópico 2 (28000-11000 BP) se suceden una serie de estadiales e interestadiales de desigual duración e intensidad (GROOTES et al., 1993; MESSE et al.,
1994; SOWERS et al., 1993; GRIP MEMBERS, 1993). Es ahora cuando se alcanzan los registros termométricos más bajos de la glaciación (Último Máximo Glaciar), situándose este momento en torno al 18000/19000 BP (Solutrense). El incremento del hielo sobre los continentes y océanos provocó la retirada de la línea de costa, disminuyendo la altura del nivel del mar entre 120 y 140 m. Uriarte (2003) señala que el Frente Polar se situaría a una latitud de $40^{\circ} \mathrm{N}$ lo que explica el predominio de condiciones glaciares en casi toda Europa.

Estas condiciones frías se vieron interrumpidas por los interestadiales de Maisiêres (27000-29000 BP) (RIVERA ARRIZABALAGA, 2004), Tursac-Salpêtrière (21000-23000 BP), Complejo Würm II fase IX (hacia el 21500 BP) y Laugerie (18500-20000 BP o 22100 cal. BP y 23450 cal. BP) (BARD et al., 1993), justo después del fuerte enfriamiento registrado en torno al $24000 \mathrm{BP}$ conocido como Evento Heinrich 2 o H2 (SHACKLETON et al., 1973). Según los datos obtenidos en los sondeos de Groenlandia, a partir del 21000 cal. BP tiene lugar el Greenland Stadial 2 (GS-2) dentro del cual se pueden diferenciar tres subfases distintas. La primera (GS-2c) se desarrolla entre el 21000 y el 19000 y es bastante fría (Solutrense). La segunda (GS-2b) tiene lugar entre el 19000 y el 16500 cal. BP (Magdaleniense Inferior) y muestra una paulatina tendencia al atemperamiento termométrico que concluye bruscamente con el evento Heinrich 1 (16500 cal. BP). A continuación, durante unos 3000 años (GS-2a) el clima sigue siendo frío pero evoluciona lentamente hacia condiciones templadas (RIVERA ARRIZABALAGA, 2004).

A lo largo de este lapso temporal, la cronología tradicional reconoce tres interestadios cálidos que reciben el nombre de Laugerie (18500-20000 BP o 22100 cal. BP 
y 23450 cal. BP), Lascaux (16500-18000 BP o 19710 cal. BP y 21342 cal. BP) y Prebolling (13700-14850 BP o 16287 cal. BP y 17852 cal. BP). Sin embargo, algunos trabajos recientes (SÁNCHEZ GOÑI, D’ERRICO, 2005) ponen en duda su existencia ya que no se detectan en los núcleos de hielo de Groenlandia y además su identificación se basa en la aparición puntual de taxones termófilos en conjuntos dominados por herbáceas.

Bruscamente, a partir del 14500 cal. BP (coincidiendo con la oscilación D/O1) las temperaturas se disparan (Bölling o Gl-1e o interestadial de Meiendorf) alcanzándose registros termométricos similares a los actuales, junto con elevados valores de humedad (URIARTE, 2003). Todo ello supuso la reforestación del territorio mediante bosques de caducifolias dominados por Quercus robur (SÁNCHEZ GOÑI, D’ERRICO, 2005).

Tras el breve enfriamiento del Older Dryas (Gl-1d), que apenas duró unas decenas de años, vuelven a instaurarse condiciones templadas (Gl-1c o Allerod) aunque con registros termométricos inferiores a los constatados durante el Bölling, lo que implica un significativo desarrollo de los bosques de caducifolias. Iriarte (2010) señala que en este período dominaba el Pinus sylvestris aunque también hay caducifolios como el avellano, roble, aliso e incluso sauce y olmo. Tras una nueva y efímera fase fría (Gl-1b) acaecida en torno al 13000 cal. BP, el Interestadio concluye mediante una breve fase menos fría (Gl-1a) que anuncia ya el fuerte enfriamiento del Younger Dryas (GS-1) durante el cual retornan condiciones similares a las del Último Máximo Glaciar. Este período se prolonga hasta el $11600 \mathrm{BP}$ y concluye tan bruscamente como se había iniciado. Se estima que las temperaturas en el Atlántico Norte descendieron entre 10 y $15^{\circ}$ (URIARTE, 2003) lo que sin duda provocó una fuerte disminución de la masa arbórea existente. Así durante el Magdaleniense Superior encontramos pino junto con algunos taxones mesófilos como el roble o el avellano. Sin embargo, durante las fases más frías se observa una brusca disminución de la vegetación arbórea (caída de AP) y una expansión de las herbáceas predominando los paisajes abiertos (IRIARTE, 2009).

El paso del Pleistoceno al Holoceno suele reflejarse en los yacimientos que conservan vestigios de explotación de recursos marinos, por la sustitución de Littorina littorea (típica de ambientes fríos) por Osilinus lineatus (ambientes templados), aunque dicho relevo fue un proceso gradual, relativamente rápido (GONZÁLEZ MORALES, 1982). En Santa Catalina predomina Littorina littorea en el nivel I $(10530 \pm 110$-en torno a $12400 \mathrm{cal}$. $\mathrm{BP}-$ y $9510 \pm 270 \mathrm{BP}$-hacia $10850 \mathrm{cal}$. BP-) (BERGANZA, 2005), mientras que en Ekain es dominante Osilinus lineatus en el nivel II datado en $9540 \pm 300$ BP -aproximadamente 10850 cal. BP-. Como señala GUTIÉRREZ ZUGASTI (2009), en los yacimientos del Magdaleniense Superior-Final y Aziliense tiene mayor proporción Littorina littorea, mientras que Osilinus lineatus predomina en los yacimientos cantábricos mesolíticos y neolíticos, lo que subraya el importante cambio climático acaecido en el tránsito Pleistoceno-Holoceno.

En un breve lapso de tiempo, se pasa de unas condiciones climáticas glaciares a otras interglaciares más templadas y húmedas, lo que implica una importante transformación medioambiental al sustituirse unas especies por otras, sobre todo en el ámbito vegetal y faunístico. Los paisajes abiertos del Dryas son reemplazados por otros arbóreos.

\subsection{Evolución del nivel marino durante el Pleis- toceno Superior y el Holoceno}

La rápida y espasmódica elevación del nivel del mar tras el Último Máximo Glaciar (LMG) (BARD et al., 2010; LIU et al., 2004; BLANCHON, 2011; GORNITZ, 2013), supuso una drástica reducción de la superficie continental disponible y utilizable por parte de los grupos humanos que ocupaban y/o explotaban estos territorios. En la mayor parte de los casos, durante los momentos álgidos de la transgresión marina, tuvieron lugar importantes cambios medioambientales (aumento de las temperaturas y de las precipitaciones y drásticas transformaciones tanto de la vegetación como de la fauna), lo que determinó la desaparición de diversos ecosistemas ricos en recursos, la aparición de otros nuevos y, sobre todo, la modificación de los paisajes, lo que obligó a los grupos humanos a adoptar nuevas estrategias de gestión y explotación del territorio o a adaptar las ya existentes.

En los últimos años la información paleoambiental disponible se ha enriquecido y diversificado considerablemente, lo que nos ha permitido, por un lado, cartografiar los fondos marinos entre las batimétricas de -10 y -105 metros, y por otro, reconstruir los principales eventos paleoclimáticos acaecidos durante el Pleistoceno y el Holoceno, así como los diversos paisajes vegetales (y la fauna asociada a ellos) existentes a lo largo del período considerado.

Pese a todo, todavía no es posible elaborar una curva de alta resolución que recoja las variaciones del nivel del mar durante los últimos 30000 años. La única aproximación es la efectuada por GUTIÉRREZ ZUGASTI (2009), el cual, utilizando datos locales, regionales y, sobre todo, globales, ha diseñado una curva del ascenso del nivel del mar para el Cantábrico que abarca desde el 15600 cal. BP hasta el 5500 cal. BP.

La información obtenida a partir del estudio de diversas terrazas coralinas de la isla de Barbados, de Tahití, de Huon (Nueva Guinea) y de diversos puntos situados en el océano Pacífico (LIU et al., 2004; URIARTE, 2003), junto con la información proporcionada por diversos sondeos realizados en el Golfo de Bizkaia (FAIRBANKS et al., 1989; EDWARDS, 1993; HANEBUTH, 2000; SÁNCHEZ GOÑl et al., 2005), ponen de manifiesto que la fusión de la mayor parte de las masas de hielo del Hemisferio Norte se inició entre el 20000 y el 19000 BP (CLARK et al., 2009), prolongándose hasta el 8000 BP. Estos aportes 


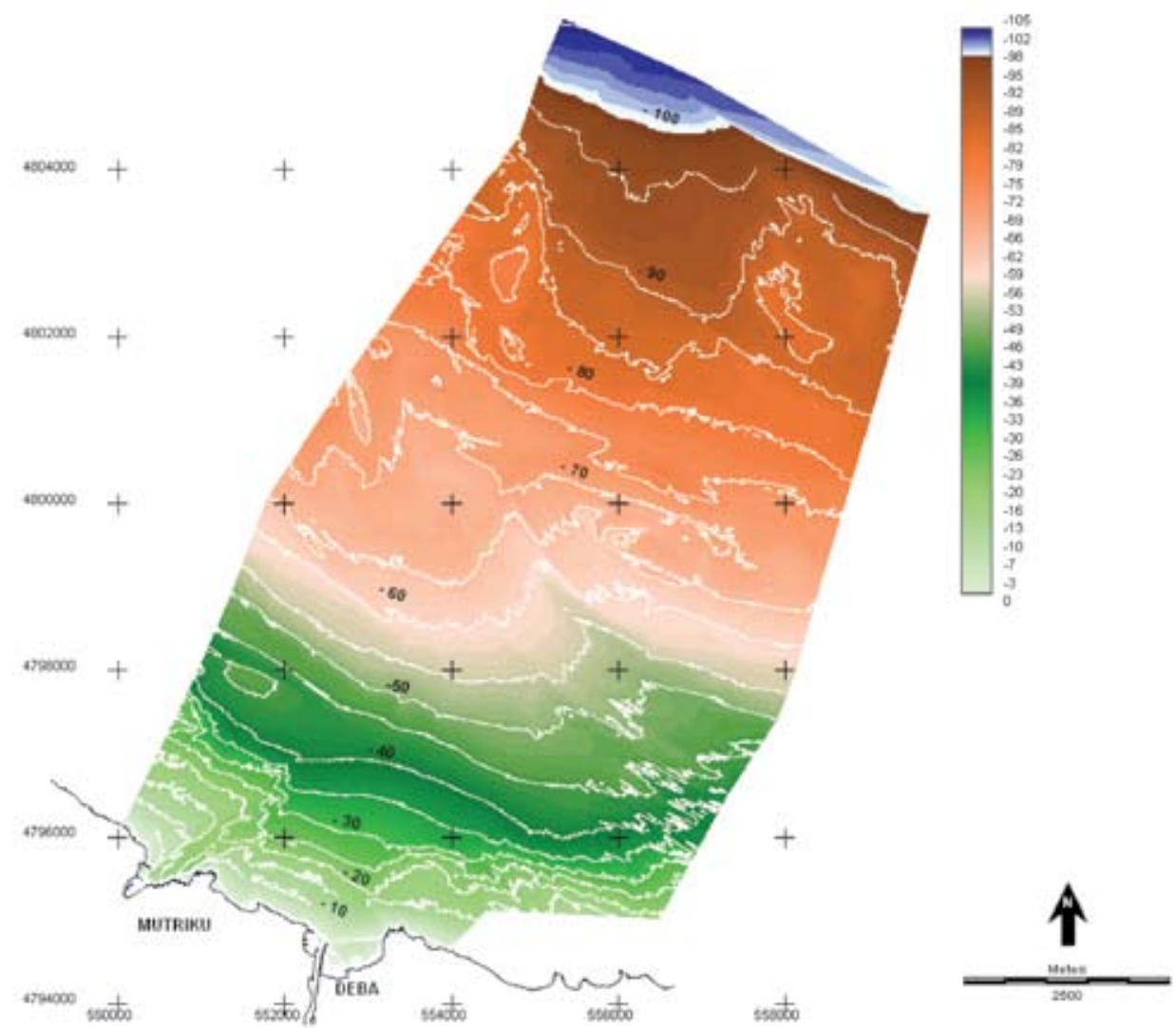

Fig. 7. Localización de la línea de costa $(-100 \mathrm{~m})$ durante el Solutrense. / Coastline location during the Solutrean period $(-100 \mathrm{~m})$.

\begin{tabular}{|c|c|c|c|c|c|}
\hline \multicolumn{6}{|c|}{ EVOLUCIÓN DEL NIVEL MARINO DURANTE EL PLEISTOCENO SUPERIOR Y HOLOCENO } \\
\hline Nivel marino metros & $\begin{array}{c}\text { Distancia a la línea de } \\
\text { costa Km }\end{array}$ & Pulso transgresivo & Fecha BP (no cal.) & & Momento cultural \\
\hline $0 a+2 m$ & $-0,01$ a $-0,05$ & mwp-1d & 7500 & $\mathrm{H}$ & \\
\hline-10 & 0,3 a 0,75 & Ninguno & 8400 & $\begin{array}{l}\mathrm{O} \\
\mathrm{L}\end{array}$ & Epipaleolítico \\
\hline-20 & 0,7 a 1,1 & mwp-1c & 9300 & 0 & \multirow{4}{*}{ Aziliense } \\
\hline-30 & 1,2 a 1,7 & \multirow{4}{*}{ MWP-1B } & 9600 & C & \\
\hline-40 & 2,1 a 2,6 & & 11000 & $\mathrm{~N}$ & \\
\hline-50 & 2,9 a 3,4 & & 11300 & 0 & \\
\hline-60 & 3,8 a 5,5 & & 11400 & $P$ & Magd. Superior-Final \\
\hline-70 & 5,9 a 6,6 & \multirow{3}{*}{ MWP-1A } & 13500 & $\mathrm{~L}$ & \multirow{2}{*}{ Magdaleniense Medio } \\
\hline-80 & 7 a 7,6 & & 14000 & t & \\
\hline-90 & 8,8 a 9 & & 14200 & S & Magdaleniense Inferior \\
\hline-100 & 10,5 & Final de mwp-2b & 17500 & $\mathrm{~T}$. & \multirow{4}{*}{ Solutrense } \\
\hline-105 & 11,2 & mwp-2b & 17800 & & \\
\hline-110 & $>12$ & \multirow[b]{2}{*}{ mwp-2a } & 19000 & U & \\
\hline$-120 a-130$ & $>12$ & & >19500 (LMG) & P. & \\
\hline
\end{tabular}

Tabl. 3. Evolución del nivel marino durante el final del Pleistoceno Superior y Holoceno. / Sea-level evolution during the Upper Pleistocene and Holocene. 


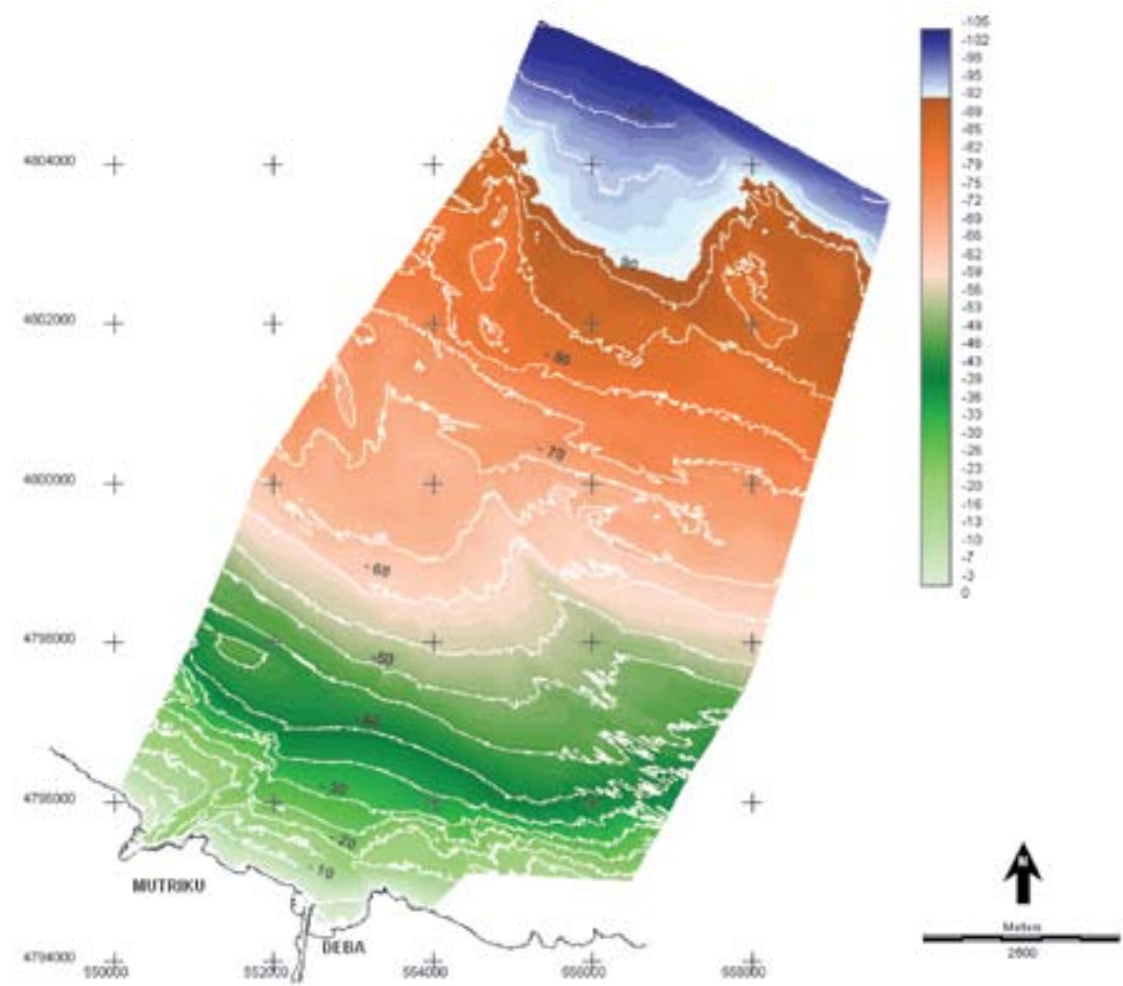

Fig. 8. Localización de la línea de costa (-90 m) durante el Magdaleniense Inferior. / Coastline location during the Lower Magdalenian period (-90m).

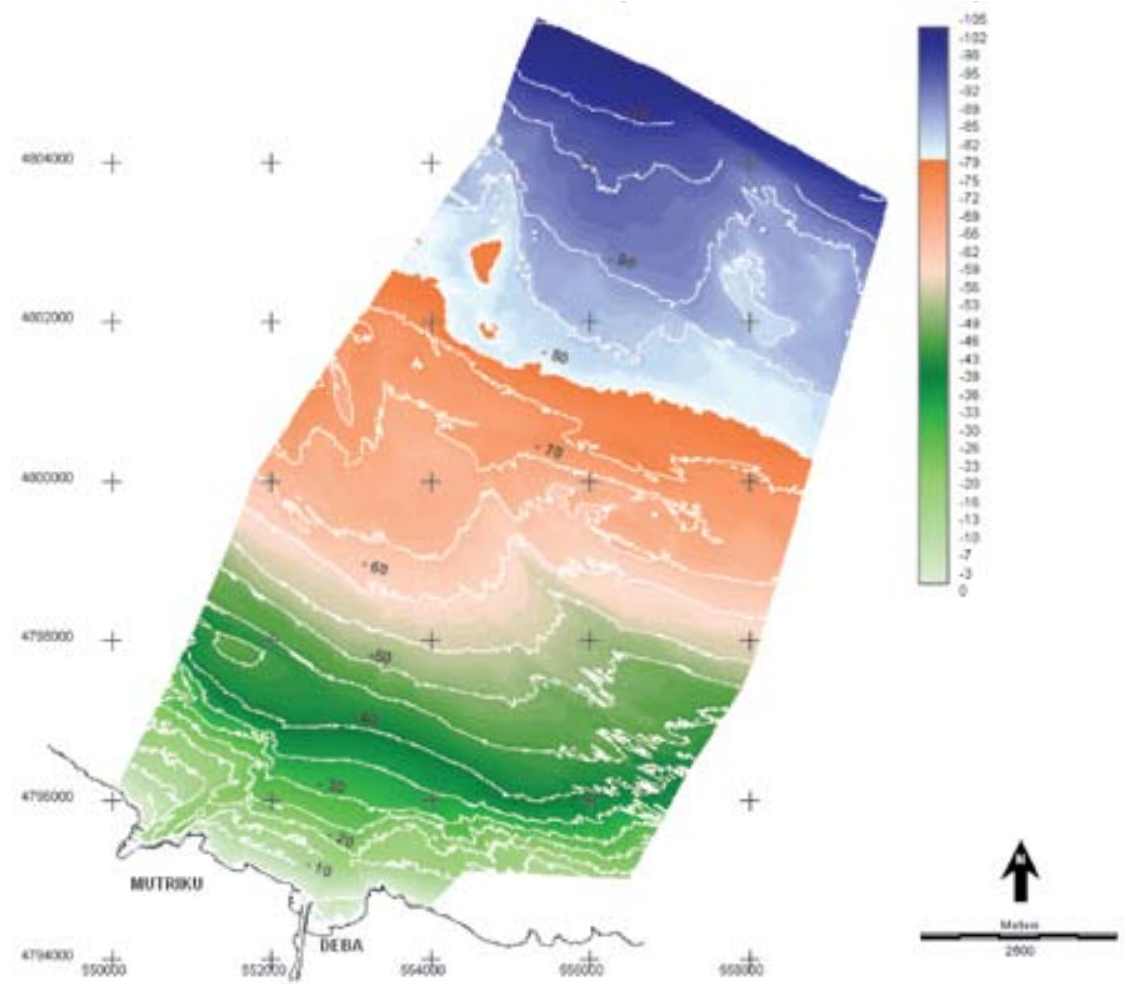

Fig. 9. Localización de la línea de costa (-80 m) durante el Magdaleniense Medio. / Coastline location during the Middle Magdalenian period (-80m). 


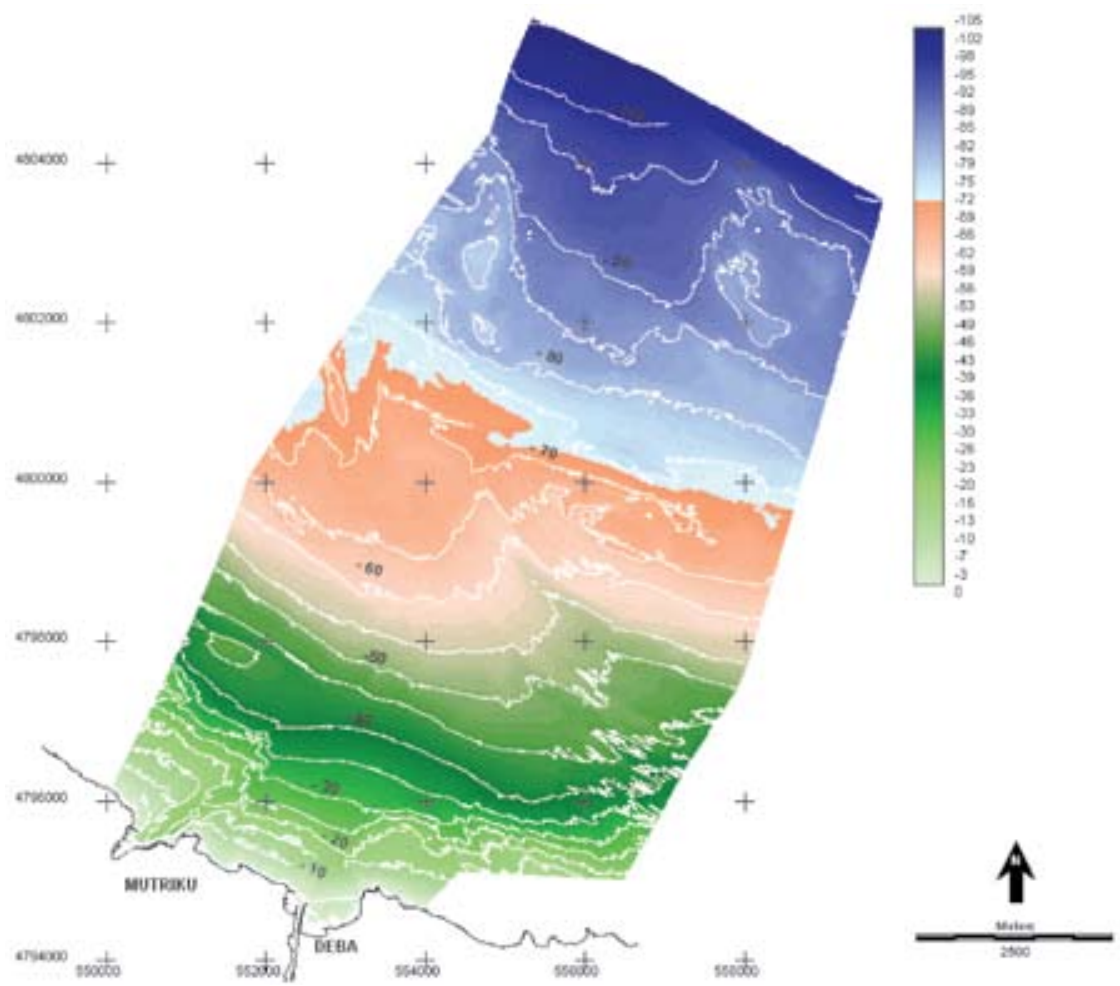

Fig. 10. Localización de la línea de costa $(-70$ m) durante el Magdaleniense Medio. / Coastline location during the Middle Magdalenian period (-70m).

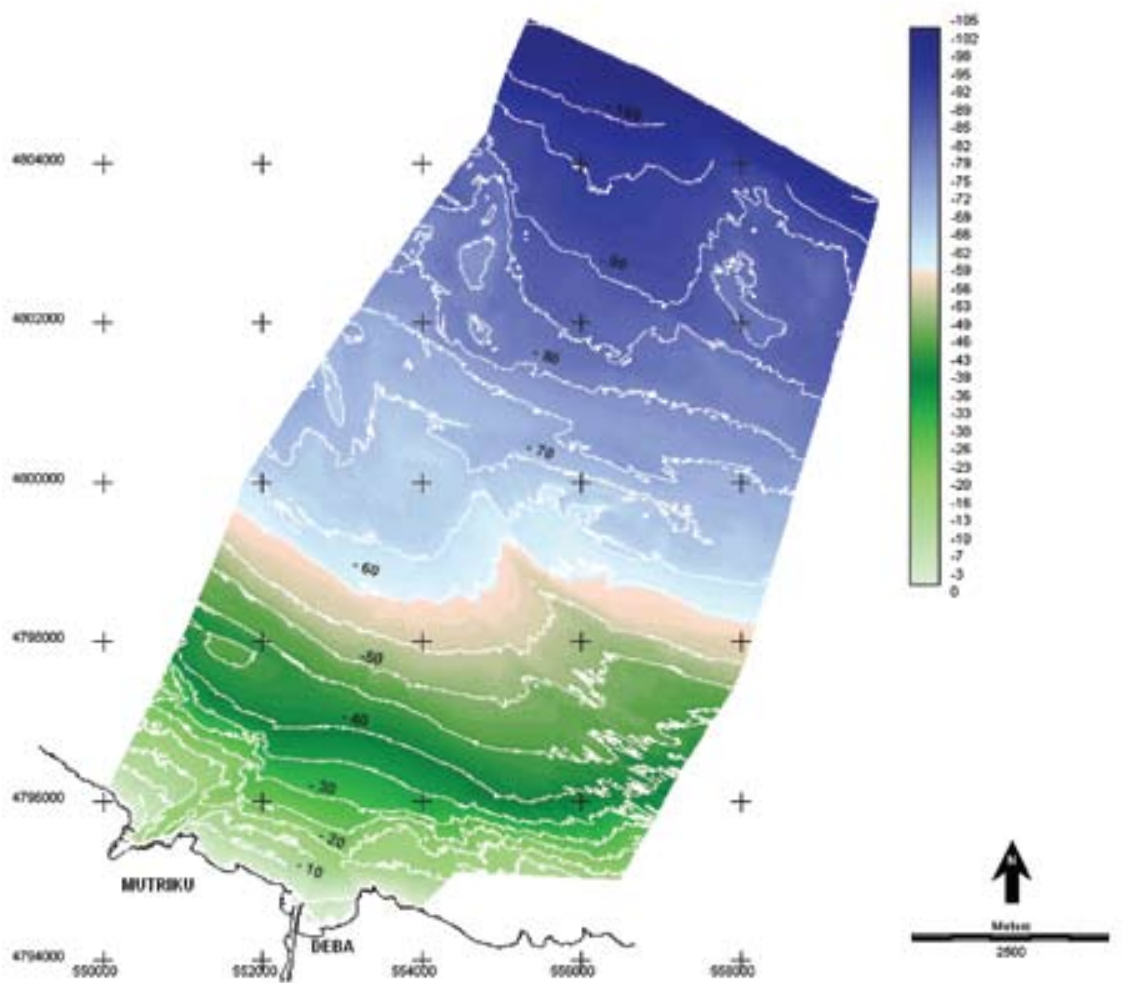

Fig. 11. Localización de la línea de costa (-60 m) durante el Aziliense. / Coastline location during the Azilian period (-60m). 
hídricos, junto con la expansión del agua del mar como consecuencia de su incremento térmico, provocaron la rápida elevación del nivel del mar y el anegamiento de la plataforma continental emergida. Sin embargo, esta elevación no fue lineal ni continua, constatándose una serie de pulsiones (MWP, melt water pulse) principales separadas entre sí por períodos más o menos prolongados de tiempo durante los cuales el mar se estabiliza, asciende suavemente o incluso retrocede ligeramente.

A tenor de los conocimientos actualmente disponibles, podemos diferenciar 6 pulsiones transgresivas en los últimos 20000 años: mwp-2a, mwp-2b, MWP-1A, MWP-1B, mwp-1c y mwp-1d (Tabl. 3).

Tal y como hemos señalado anteriormente, la deglaciación ya se había iniciado en el 20000 BP. En esos momentos el nivel del mar se localizaba unos $120 \mathrm{~m}$ por debajo de su posición actual (algunos autores rebajan esta cifra situándola en torno a los -140 m), lo que situaría la línea de costa a más de $12 \mathrm{~km}$ de distancia (Solutrense). En torno al 19200 BP tiene lugar la pulsión mwp-2a elevándose unos $11 \mathrm{~m}$ el nivel del mar en apenas 400 años (LIU et al., 2004), lo que se traduce en un ascenso medio de 2,75 m por siglo. Esta primera pulsión coincide con el calentamiento experimentado por el clima durante el interestadial de Laugerie (18500-20000 BP/22100-23450 cal. BP).

Entre el 18800 y el 18000 BP el nivel marino permanece estable (o disminuye ligeramente) bajo condiciones climáticas frías. Coincidiendo con la controvertida oscilación climática de Lascaux (SÁNCHEZ GOÑI, D’ERRICO, 2005) tiene lugar la pulsión mwp-2b (18000-17500 BP), la cual provoca una elevación del nivel marino de unos 9 m en 500 años (1,8 m por siglo). Al finalizar la pulsión, el nivel del mar se sitúa a unos -105 m y la línea de costa a unos 11,2 km de distancia (Fig. 7).

A lo largo del Magdaleniense Inferior (aproximadamente 14400-17000 BP; 17550 y 20300 cal. BP) el nivel del mar permanece estable e incluso disminuye ligeramente. La línea de costa se localiza entre 10,5/11 km de distancia y el nivel del mar unos $100 \mathrm{~m}$ por debajo de su posición actual. Durante la mayor parte de este período predominan las condiciones climáticas frías. A partir del $15000 \mathrm{BP}$ se inicia un suave ascenso que desemboca en la pulsión MWP-1A. Como señala URIARTE (2003) fue la primera pulsión de fusión intensa, con una subida global de más de $30 \mathrm{~m}$ en aproximadamente 1200 años, pasando de -100 a -68 m. (Figs. 8, 9 y 10). Considerando únicamente la fase "paroxismal", la elevación fue de unos $20 \mathrm{~m}$ en 500 años (4 m por siglo). Todo ello determina que hacia el 13600 BP (16650 cal. BP) la línea de costa se situaba unos $6 \mathrm{~km}$ al norte de su posición actual (Figs. 11 y 12). La causa que ocasionó este rápido ascenso (CLARK, 2002; CLARK et al., 2004; ALLEY, 2000) fue el deshielo parcial de la Antártida, el cual provocó la

\footnotetext{
${ }^{1}$ Las siglas en mayúscula indican los pulsos principales, mientras que las que aparecen en minúsculas indican elevaciones secundarias o poco marcadas.
}

alteración del circuito termohalino de las corrientes oceánicas, lo que acabó afectando al Hemisferio Norte, con mayor producción de agua profunda, intensificación de la corriente del Golfo y calentamiento del Atlántico Norte (WEAVER, 2003; URIARTE, 2003). Esta fusión puede relacionarse con el período templado denominado PreBolling-Angles, acaecido entre el 13700 y el 14850 BP (16287-17852 cal. BP) (MENÉNDEZ et al., 1997).

El análisis de los perfiles batimétricos muestran una brusca ruptura de pendiente entre los -90 y los $-100 \mathrm{~m}$ (Fig. 16) y entre los -70 y los -80 m (Figs. 17 y 18), lo que probablemente se relaciona con 2 antiguos acantilados modelados, uno durante la larga estabilización del nivel marino acaecida en el Solutrense-Magdaleniense Inferior, antes de la pulsión MWP-1A, y el otro tras la estabilización ocurrida una vez finalizada dicha pulsión.

Entre el 13500 y el 12000 BP (aproximadamente 16200-14070 cal. BP) el nivel del mar permanece estable $\mathrm{o}$ asciende muy suavemente, hasta que se produce la pulsión MWP-1B, la cual se relaciona con el cálido interestadial Bölling y parte del Allerod (incluyendo el efímero estadial frío denominado Oldest Dryas) (BASSET et al., 2005). En apenas 700 años el nivel marino se elevó unos 20 m. Hacia el 11200 BP -13100 cal. BP- (Magdaleniense Final), la línea de costa se situaba a unos 2,1 km de distancia y el nivel medio del mar a -40 m. (Fig. 13). La causa que explica esta rápida elevación se relaciona con los elevados registros térmicos acaecidos justo después del Younger Dryas (Dryas III), es decir a comienzos del Holoceno.

A partir del 11000 BP (12900 cal. BP), el mar asciende suavemente situándose la línea de costa a unos $1200 \mathrm{~m}$ de distancia (-30/-32 m) (Figs. 14 y 15) en torno al 9500 BP (10750 cal. BP) (Aziliense). Un nuevo pulso transgresivo (mwp-1c) tuvo lugar entre el 9500 y el 9000 BP (10750-10200 cal. BP), el cual supuso una significativa elevación del nivel del mar, hasta situarse éste en torno a los $-10 \mathrm{~m}$. La línea de costa se localizaba a apenas $500 \mathrm{~m}$ de distancia de la actual, lo que nos permite afirmar que el territorio presentaba ya una configuración muy similar a la que se observa en la actualidad (muchos valles fluviales habían comenzado a inundarse conformando los actuales estuarios). Una última pulsión (mwp1d) se produjo entre el 8000-7500 BP (8870-8300 cal. BP) (EDESO, 1990; EDESO et al., 2005), culminando en torno al $7000 \mathrm{BP}$ (7850 cal. BP) momento en el que el nivel marino supera en 1 ó 2 metros la altura actual. A partir del 7000 cal. BP el nivel del mar desciende ligeramente, situándose en una posición similar a la que ocupa hoy día. Posteriormente, entre el 4000 y el 3000 se constata una breve regresión $(-1 /-1,5 \mathrm{~m})$ seguida de una nueva pulsación transgresiva $(+0,5 / 1 \mathrm{~m})$ (EDESO, 1990; EDESO et al., 2005; LOPETEGl et al., 2012) que acaba desembocando en la actual configuración del litoral vasco. 


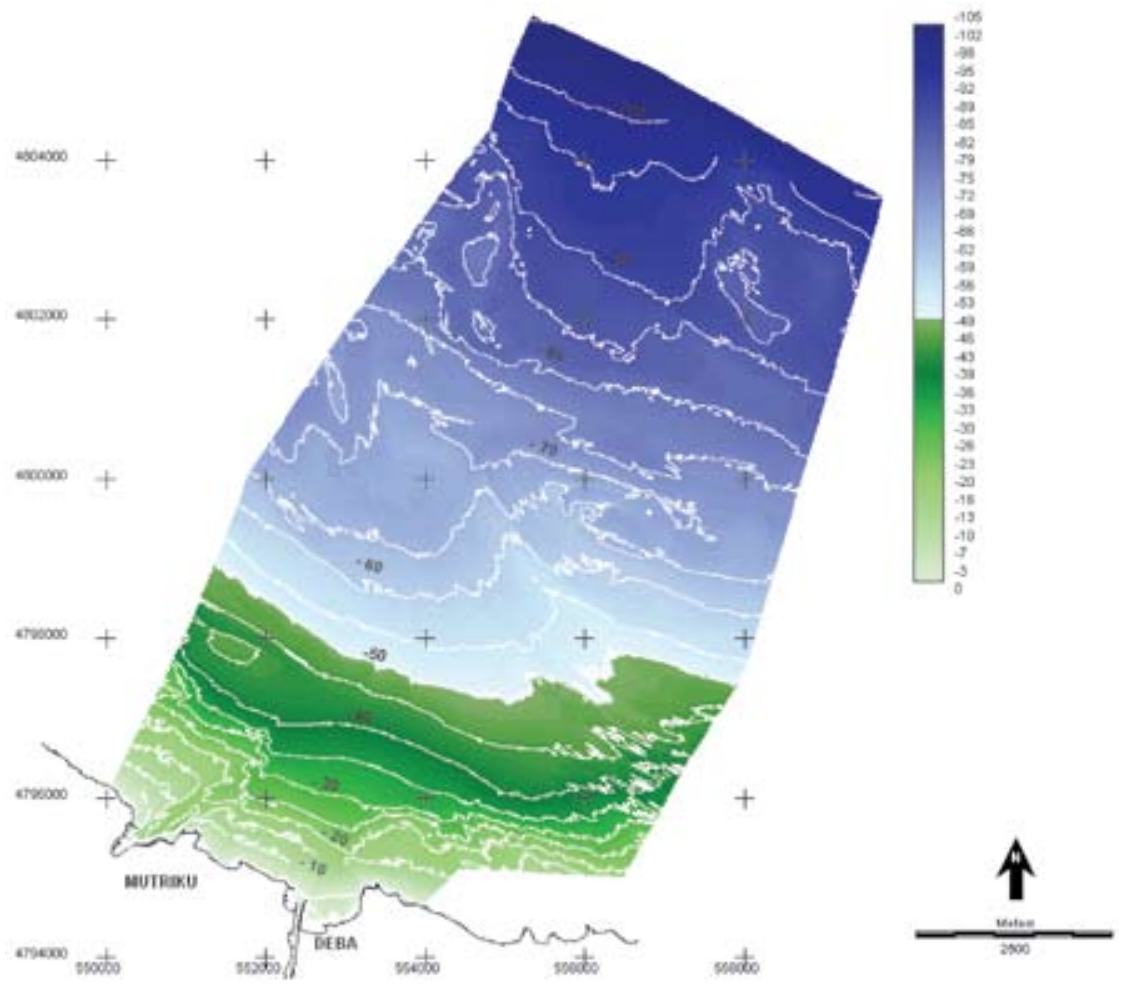

Fig. 12. Localización de la línea de costa $(-50 \mathrm{~m})$ durante el Aziliense. / Coastline location during the Azilian period (-50m).

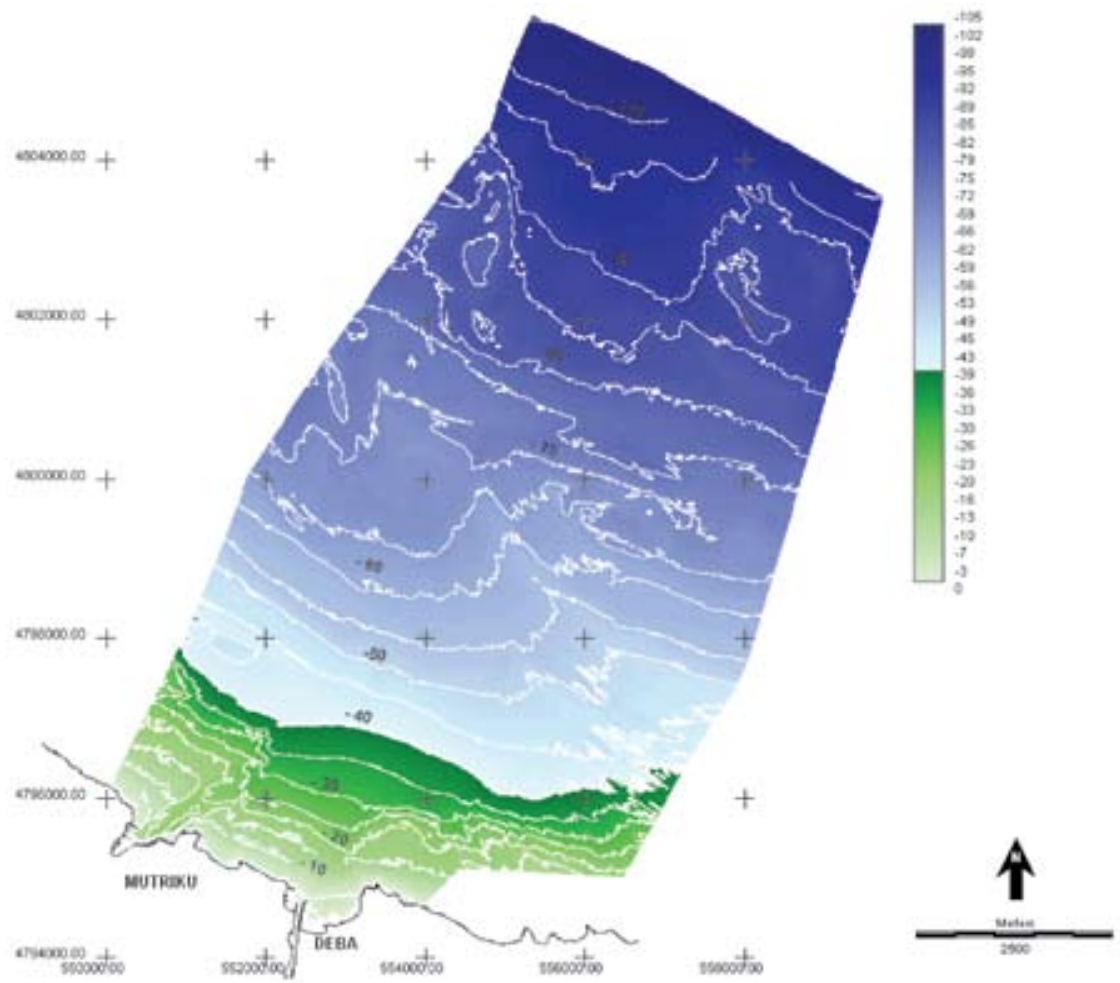

Fig. 13. Localización de la línea de costa $(-40 \mathrm{~m})$ durante el Aziliense. / Coastline location during the Azilian period (-40m). 


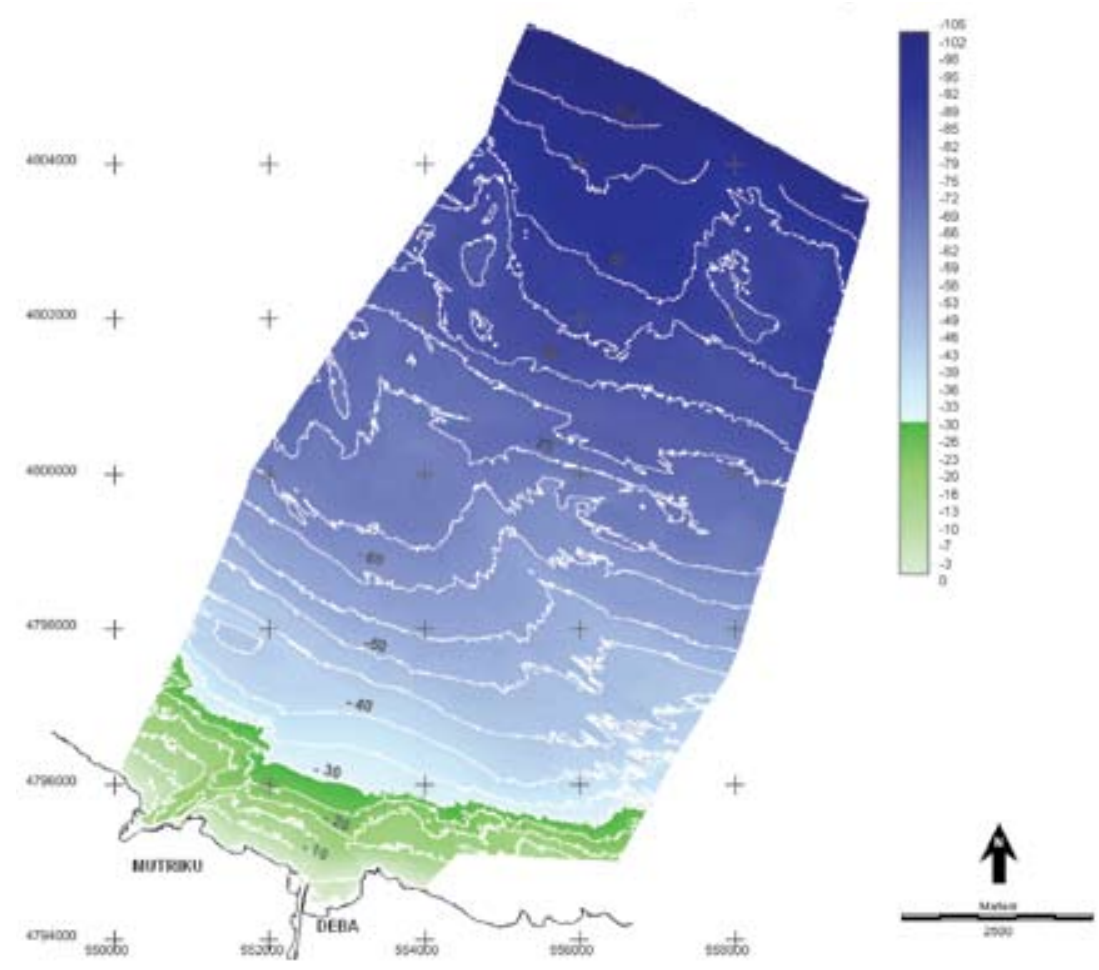

Fig. 14. Localización de la línea de costa (-30 m) durante el Aziliense. / Coastline location during the Azilian period (-30m)

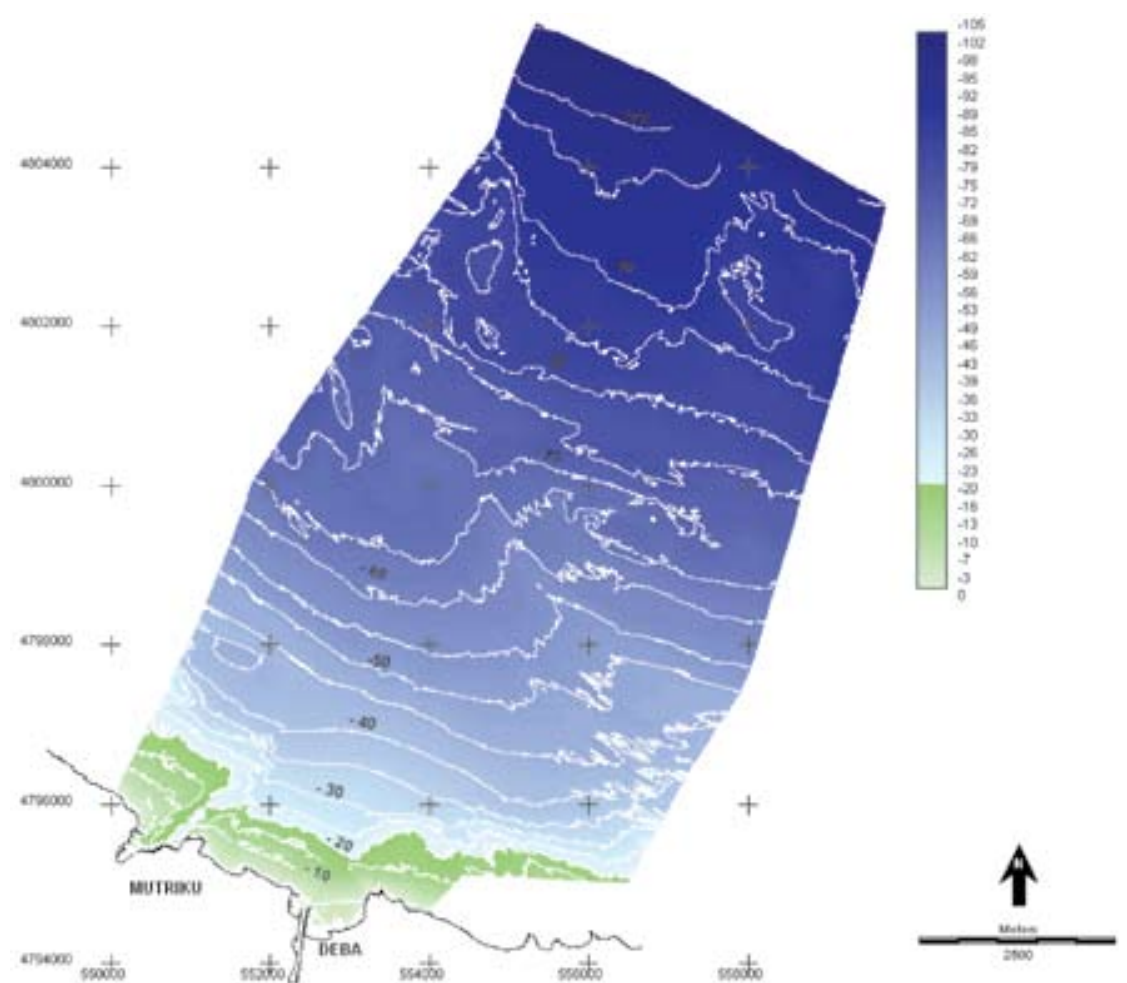

Fig. 15. Localización de la línea de costa (-20 m) durante el Aziliense. / Coastline location during the Azilian period (-20m). 


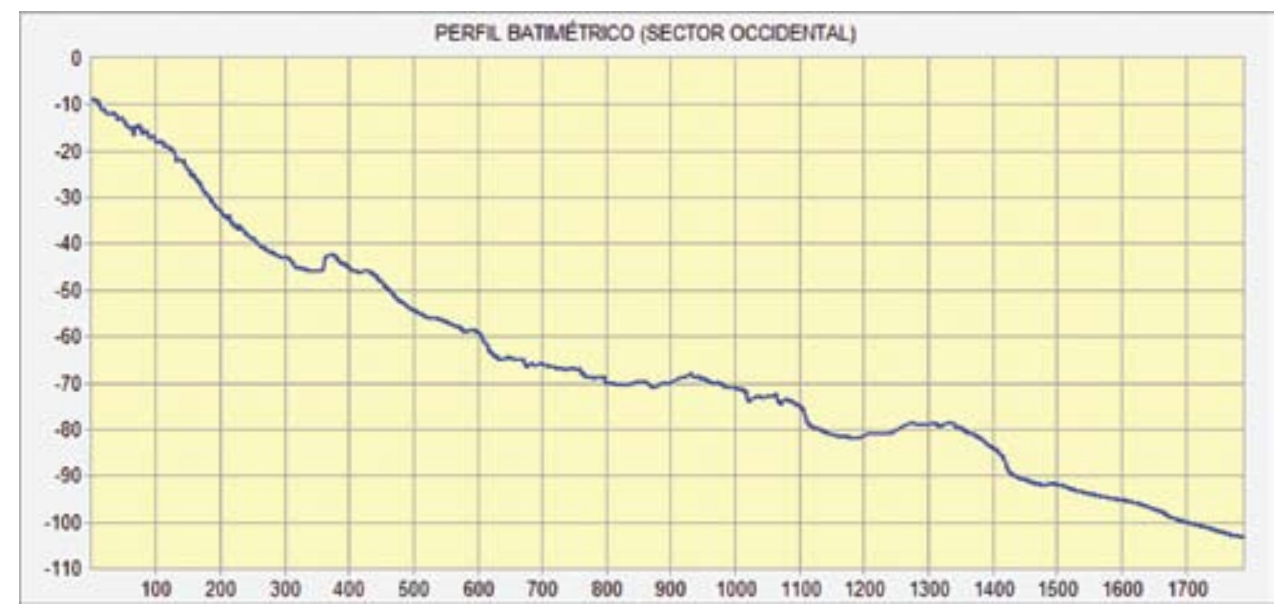

Fig. 16. Perfil batimétrico en el sector occidental de la zona de estudio (en metros). / Bathymetric profile in the western part of the area under study.

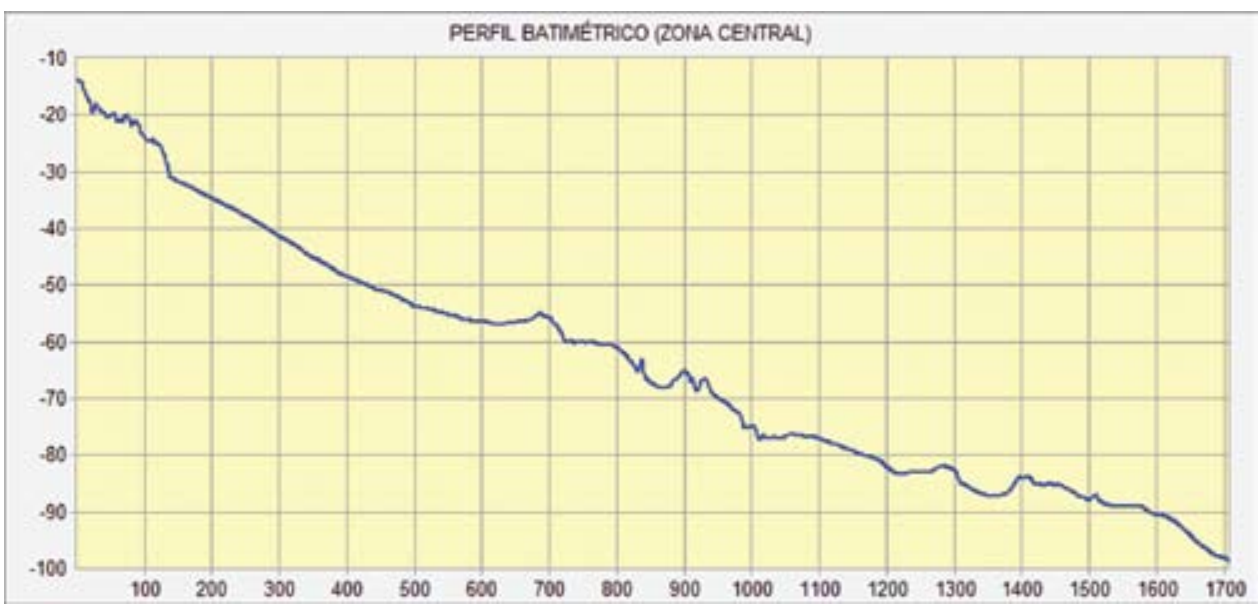

Fig. 17. Perfil batimétrico en el sector central de la zona de estudio (en metros). / Bathymetric profile in the central part of the study area.

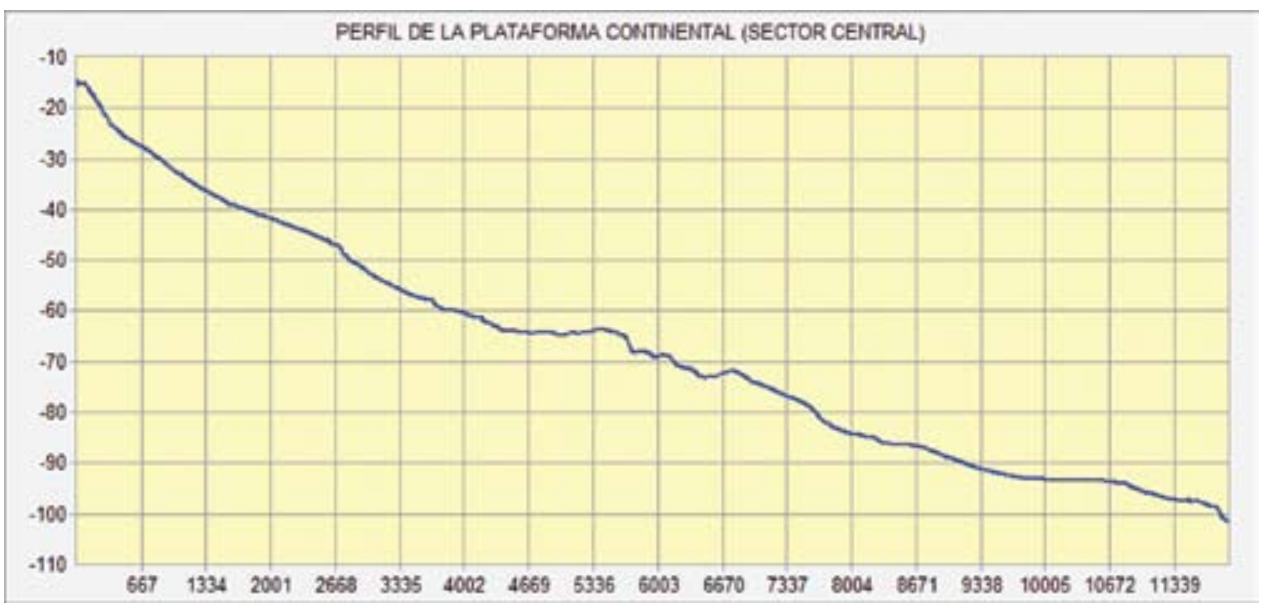

Fig. 18. Perfil batimétrico en el sector oriental de la zona de estudio (en metros). / Bathymetric profile in the eastern part of the study area. 

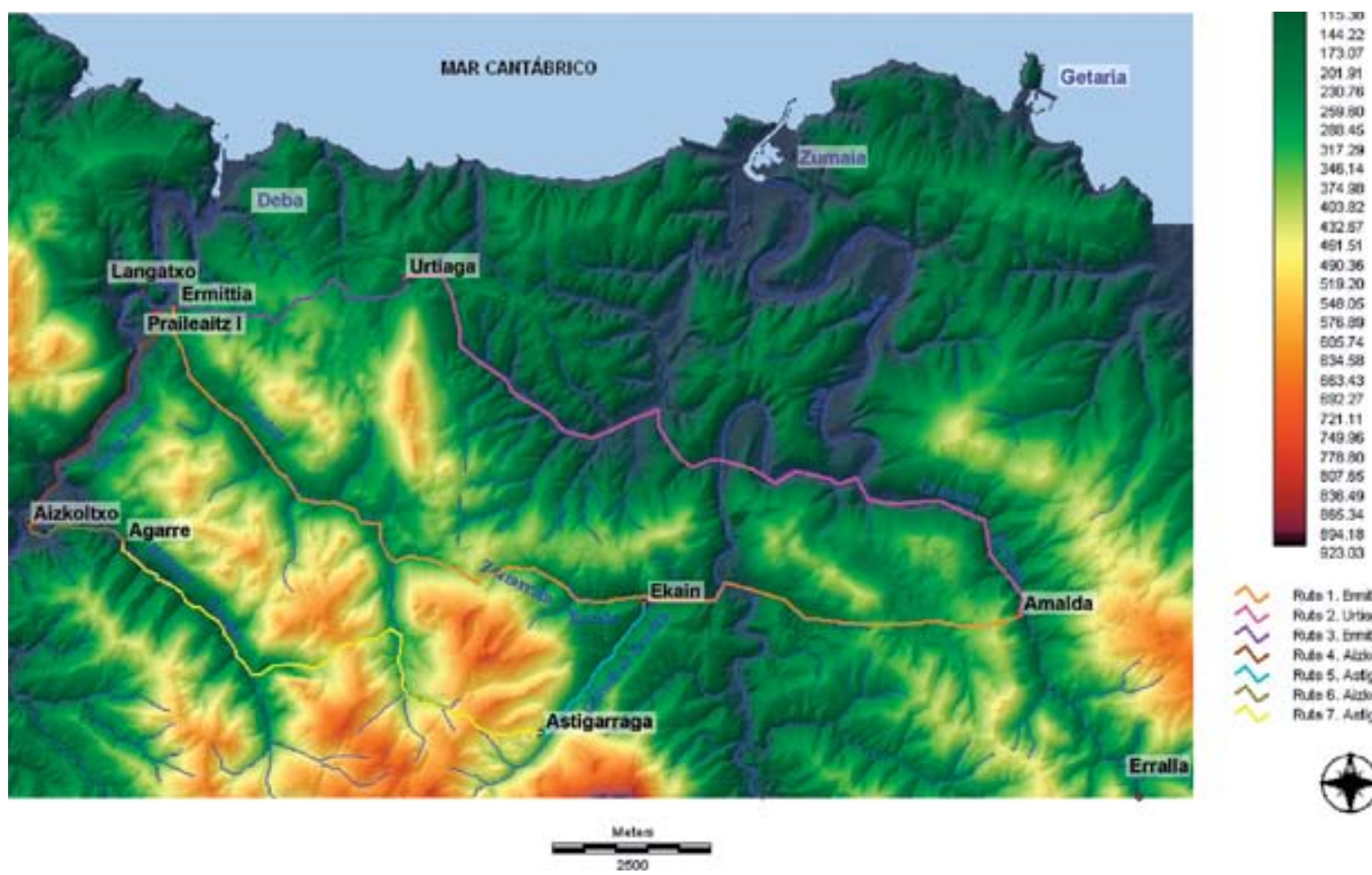

Fig. 19. Rutas teóricas utilizadas por el hombre prehistórico en distintos momentos de Paleolítico. / Theoretical routes used by prehistoric men at different times of the Paleolithic period.

\section{3.- CÁLCULO DE LAS RUTAS ÓPTIMAS ENTRE LOS DISTINTOS YACIMIENTOS}

Poco o nada sabemos sobre los desplazamientos efectuados por los distintos grupos humanos que habitaban la zona durante el final del Paleolítico Superior y el Aziliense-Epipaleolítico. Del mismo modo que los grupos primitivos actuales explotan los recursos de su entorno, los grupos humanos prehistóricos desarrollaron técnicas similares de gestión y aprovechamiento (recolección de plantas y frutos silvestres, caza, marisqueo y pesca, carroñeo...). Intentar reconstruir estos itinerarios es imposible ya que nuestros conocimientos sobre el entorno son escasos y limitados ( $y$ en algunos casos posiblemente erróneos o al menos contradictorios), e incluso sesgados por la exigua documentación referida al paisaje vegetal. Tampoco disponemos de información sobre la relación existente entre los diversos asentamientos en cada período, aunque no parece descabellado suponer que ésta debió (e incluso algún tipo de intercambio) de existir ya que las distancias entre los asentamientos son reducidas, siendo inevitable el contacto entre los individuos durante el desarrollo de sus actividades diarias (caza, recolección, etc.).

El trazado de estas hipotéticas rutas (Fig. 19 y Tabl. 4) se ha efectuado mediante el algoritmo Costpush (EASTMAN, 1989), el cual nos permite modelizar el territorio generando un mapa de fricciones (coste de movimiento) a partir de las coberturas de pendiente (entendida como una medida geométrica que define la inclinación del te- rreno), rugosidad del terreno y anisotropía de los movimientos, ya que el coste de desplazamiento es diferente dependiendo del sentido en el que se toma la pendiente (ascendente o descendente).

A partir del mapa de fricciones o costes de movimiento, se define la ruta de menor coste (camino óptimo) y una vez establecida ésta (GANSKOPP, 2000), el siguiente paso consiste en calcular el tiempo empleado en recorrer dicha ruta. Para ello asignamos a cada tramo su pendiente topográfica, expresada en tantos por ciento, así como el sentido de la misma (ascendente o descendente). No se consideran otros factores como la climatología, la vegetación o la hora del día, estimándose que en condiciones climáticas frías predominan los paisajes abiertos.

La pendiente y el tipo de terreno tienen una influencia evidente en las velocidades de desplazamiento, así como el sentido de recorrido de la pendiente, siendo su influencia máxima en las zonas más escarpadas. Para asignar la velocidad de desplazamiento a cada uno de los tramos considerados, hemos utilizado las tablas propuestas para desplazamientos a pie por el Transport and Road Research Laboratory (TRRL, 1978) y por Ochoa (2007).

La simulación se ha efectuado considerando que la persona que se desplaza es un individuo adulto (menor de 55 años) que no efectúa paradas, ni detenciones (descansos) durante su itinerario, aunque por lo general, probablemente, la premura no sería una de las características de la movilidad de los diversos grupos humanos. Tampoco encuentra obstáculos significativos durante su 
recorrido, ni se ve obligado a salvar accidentes ocasionales como ríos, cortes verticales, etc. Es decir, se estima que se trata de un desplazamiento directo, considerando como tales aquellos en los que no hay impedimentos para caminar a una velocidad constante. Teniendo en cuenta todos estos aspectos, hemos establecido 7 velocidades diferentes en función de los rangos de pendiente previamente asignados a cada tramo, por lo que el tiempo necesario para recorrer una de estas rutas es igual al sumatorio de los tiempos parciales de cada tramo.

\begin{tabular}{|c|c|c|c|}
\hline \multicolumn{4}{|c|}{ DISTANCIAS Y TIEMPOS NECESARIOS ENTRE LOS DIFERENTES YACIMIENTOS } \\
\hline Yacimientos & $\begin{array}{c}\text { Distancia en línea recta } \\
\text { (en metros) }\end{array}$ & $\begin{array}{l}\text { Distancia estimada } \\
\text { (en metros) }\end{array}$ & Tiempo invertido \\
\hline Praileaitz I-Ermittia & 302,33 & 363 & $12^{\prime}$ \\
\hline Praileaitz I-Langatxo & 365,38 & 417 & $13^{\prime}$ \\
\hline Praileaitz I-Urtiaga & 3838,70 & 4591 & 1h $58^{\prime}$ \\
\hline Praileaitz I-Agarre & 3594,36 & 4264 & 1h $58^{\prime}$ \\
\hline Praileaitz I-Aizkoltxo & 3825,12 & 4236 & 1h $41^{\prime}$ \\
\hline Praileaitz I-Ekain & 8750,20 & 9754 & 3h $38^{\prime}$ \\
\hline Praileaitz I-Erralla & 16879,44 & 18856 & 7 h $22^{\prime}$ \\
\hline Praileaitz I-Amalda & 14099,65 & 16750 & 7h 09' \\
\hline Ekain-Astigarraga & 2547,51 & 2900 & 1h $14^{\prime}$ \\
\hline Ekain-Amalda & 5798,76 & 6452 & $2 h 38^{\prime}$ \\
\hline Ekain-Urtiaga & 6218,73 & 8852 & 3h $32^{\prime}$ \\
\hline Ekain-Agarre & 8070,05 & 8850 & 3h $57^{\prime}$ \\
\hline Ekain-Erralla & 8189,94 & 9478 & 3h $16^{\prime}$ \\
\hline Ekain-Ermittia & 8545,60 & 9762 & $4 \mathrm{~h} 00^{\prime}$ \\
\hline Ekain-Langatxo & 9085,26 & 10146 & $4 \mathrm{~h} 17^{\prime}$ \\
\hline Ekain-Aizkoltxo & 9540,43 & 10502 & $4 h 35^{\prime}$ \\
\hline Urtiaga-Ermittia & 3539,76 & 4228 & 1h $48^{\prime}$ \\
\hline Urtiaga-Langatxo & 4021,02 & 4898 & $2 \mathrm{~h} 13^{\prime}$ \\
\hline Urtiaga-Agarre & 5924,12 & 6804 & $2 h 54^{\prime}$ \\
\hline Urtiaga-Aizkoltxo & 6896,19 & 7806 & 3h $17^{\prime}$ \\
\hline Urtiaga-Astigarraga & 7302,76 & 11552 & $4 \mathrm{~h} 40^{\prime}$ \\
\hline Urtiaga-Amalda & 10815,11 & 13802 & $4 \mathrm{~h} 17^{\prime}$ \\
\hline Urtiaga-Erralla & 13852,00 & 15562 & $4 h 46^{\prime}$ \\
\hline Erralla-Amalda & 3338,50 & 3966 & $57^{\prime}$ \\
\hline Erralla-Agarre & 13856,33 & 18328 & $7 \mathrm{~h} 13^{\prime}$ \\
\hline Erralla-Aizkoltxo & 17600,32 & 19984 & $7 \mathrm{~h} 51^{\prime}$ \\
\hline Ermittia-Erralla & 16655,94 & 18910 & $7 \mathrm{~h} 22^{\prime}$ \\
\hline Ermittia-Agarre & 3727,09 & 4217 & 1h $58^{\prime}$ \\
\hline Ermittia-Aizkoltxo & 4049,86 & 4189 & 1h $42^{\prime}$ \\
\hline Ermittia-Astigarraga & 8651,94 & 10060 & $4 \mathrm{~h} 14^{\prime}$ \\
\hline Amalda-Ermittia & 13853,43 & 16538 & 6 6h $52^{\prime}$ \\
\hline Agarre-Aizkoltxo & 1473,32 & 1652 & $38^{\prime}$ \\
\hline Agarre-Astigarraga & 7064,61 & 8732 & 3h $44^{\prime}$ \\
\hline Astigarraga-Aizkoltxo & 8502,21 & 9518 & $4 \mathrm{~h} 22^{\prime}$ \\
\hline
\end{tabular}

Tabl. 4. Posibles itinerarios entre los diversos asentamientos. / Possible routes between various human settlements.

Sin embargo, el problema que se plantea en relación a esta cuestión es si las ocupaciones de dichas cavidades son estrictamente contemporáneas, tanto desde el punto de vista cultural como del cronológico, hecho que no puede ser dilucidado con los actuales métodos de datación. Los restos correspondientes a un mismo nivel pueden pertenecer a fechas muy diferentes dentro del mismo periodo cultural, pudiendo haber discurrido décadas o siglos entre unas evidencias y otras. Aún coincidiendo las fechas radiocarbónicas no habría demasiadas garantías, ya que podrían corresponder a distintos grupos coetáneos. En la práctica, hoy día, es imposible probar de forma irrefutable que es el mismo grupo humano el que ha ocupado dos de las cavidades, salvo que encajaran o se unieran entre ellos objetos procedentes de ambos lugares, futura línea de investigación gracias a la aplicación de nuevas tecnologías. 
Una de las características de los grupos humanos paleolíticos es su notable movilidad, como se ha intuido tradicionalmente por las características de la cultura material (tipología, decoraciones, moluscos, etc.), pero han sido los diferentes estudios sobre la procedencia del sílex efectuados por Tarriño (2006), los que han aportado información objetiva suficiente para comenzar a entender la movilidad de estos grupos o sus contactos. Las principales variedades de sílex son las del Flysch (Barrika, Gaintxurizketa, etc.), Trebiño, Urbasa, Salies de Béarn, Chalosse, etc. Sin embargo, si bien el aprovisionamiento de sílex en algunos lugares -actividad probablemente estacional en aquellos afloramientos más elevados: Urbasa, Treviño- fue una de las razones fundamentales que obligaba al desplazamiento, esta actividad se insertaría en el conjunto de otra serie de necesidades, como son las relacionadas con su subsistencia (recolección de frutos, caza, etc.) y con la de establecer y mantener relaciones sociales y de intercambio con otros grupos humanos.

El nivel más antiguo estudiado en Praileaitz I corresponde al Solutrense, -a pesar de que existen otros restos más antiguos-, y es contemporáneo en el entorno más próximo al de las cuevas de Urtiaga, Ermittia -Deba-y Amalda -Zestoa-, y hacia el este, de Aitzbitarte IV y al oeste, de Bolinkoba, Antoliña, Arlanpe, etc. A estas ocupaciones se superpone el Magdaleniense Inferior, periodo sobre el que durante las últimas décadas se ha producido un notable enriquecimiento de la información disponible en el territorio guipuzcoano, apareciendo bien individualizado y definido en Erralla (V), Ekain (VII), Amalda y en Praileaitz I, donde presenta características muy singulares. Hacia el este podemos señalar Aitzbitarte IV y al oeste su presencia es evidente en Bolinkoba, Antoliña y en Santimamiñe, yacimiento este último donde se recuperó una azagaya de base hendida de sección circular -objeto excepcional- que presenta una gran similitud con la de Praileaitz I (PEÑALVER, MUJIKA, 2005).

A la luz de las dataciones disponibles y de la información existente, podemos afirmar que tras el desarrollo del final del Magdaleniense Inferior y del Magdaleniense Medio (15.000 y 14.000 BP, -18.250 y 17.250 cal. BP-), periodo escasamente representado en la zona, se constata un notable incremento del número de ocupaciones conocidas en el entorno más próximo a Praileaitz I, no quizás tanto por un aumento de la población como por una reducción de la franja de territorio situado entre las zonas kársticas con yacimientos y la orilla del mar (paulatina inundación de la plataforma continental). Durante el desarrollo del Magdaleniense Superior/Final y Epipaleolítico los habitantes de Praileaitz I pudieron estar en relación (o proceder de dichas cavidades) con ocupantes de otras cuevas de la cuenca del Deba, como Ermittia, Urtiaga, Aizkoltxo, Agarre, Langatxo e Iruroin, y con asentamientos situados en la cuenca del río Urola (Ekain y Erralla); y ya más alejados, hacia el oeste, con los asentamientos de Lumentxa, Santa Catalina, Abittaga, además de las ya anteriormente citadas de Bolinkoba, Santimamiñe y
Antoliña (AGUIRRE, 2000; AGUIRRE et al., 2000; LÓPEZ QUINTANA, et al., 2011).

En nuestra opinión, los asentamientos con los que más estrechamente pudiera estar relacionado Praileaitz I, por su proximidad -a tan sólo 15 minutos-, son los de Ermittia, yacimiento especializado en la caza de Capra ( 85\%) durante el Magdaleniense (en el Solutrense, cabra -56\%-, sarrio -23,5\%- y ciervo -15\%-), y Urtiaga a 2 horas de distancia, donde es dominante la caza del ciervo ( 40\%), seguido de cabra y sarrio, y ya en la cuenca del río Alzolaras, afluente del río Urola, a unas 7 horas de camino, con Amalda especializada en la caza de sarrio y Erralla, en la de cabras. También pudieron establecerse relaciones con los habitantes de Ekain (localizada en la subcuenca del Goltzibar que forma parte de la cuenca del Urola), cavidad situada a 3,30 horas y donde se abaten principalmente cervatillos durante el Magdaleniense Inferior, y cabras durante el Magdaleniense SuperiorFinal.

En el caso de Praileaitz I, y de otros yacimientos costeros, un aspecto a tener en cuenta es el entorno geográfico, el cual está sometido a rápidas e importantes transformaciones debido a las numerosas variaciones experimentadas por la línea de costa durante el Paleolítico Superior y Holoceno, como consecuencia de los diversos cambios ambientales acaecidos. En el contexto más cercano al yacimiento, menos del $6 \%$ de la superficie del territorio tiene una pendiente inferior al 10\% (la zona costera actual), y como consecuencia de su litología, este entorno se caracteriza por ser abrupto, agreste y estar dominado por pronunciadas pendientes. Es aquí donde se sitúan Praileaitz I y las otras ocupaciones solutreomagdalenienses más próximas, orientándose la actividad cinegética hacia la caza de especies características de este medio, (preferentemente en la época templada del año), que tal y como hemos indicado anteriormente son Capra en Ermittia, Cervus en Urtiaga, Cervus y Capra -una u otra según el periodo- en Ekain, y Rupicapra rupicapra en Amalda. Otros yacimientos que hemos citado anteriormente están en la actualidad en fase de estudio y valoración, por lo que no podemos establecer conclusiones definitivas sobre los mismos -Aizkoltxo, Langatxo, Iruroin y Astigarraga- (ALTUNA et al., 1984, 1985,1990).

Por el contrario, en la actual plataforma inundada -entonces emergida-, casi el $90 \%$ de su superficie tenía una pendiente inferior al 5\%, espacio más apto para especies como los bóvidos, caballos o renos, que por lo general están anecdóticamente representadas en los yacimientos que señalamos. Esta orografía más suave facilitaría la movilidad E-O, o viceversa, tanto de los grupos humanos como de las manadas, durante el Pleistoceno.

Las ocupaciones de los meses más desapacibles del año son prácticamente desconocidas en la zona (al parecer sólo unas pocas piezas fueron cazadas en esos meses en Urtiaga y Erralla), por lo que no es descartable que la mayoría de esos asentamientos invernales se localizasen en esta área geográfica, progresivamente inundada durante el Tardiglaciar, que pudo presentar unas 
condiciones climáticas más benignas por su proximidad al mar, y además aportar abundantes recursos marinos.

Por otra parte, la relación de los ocupantes de Praileaitz I, y de otros yacimientos solutreo-magdalenienses del entorno, con los recursos marinos -moluscos, mamíferos, etc.-, parece haber sido muy limitada. Esto se explicaría por la notable distancia existente entre los yacimientos y la línea de costa, que en aquellas fechas estaba a unos 10,5-12 km, aunque durante el desarrollo del Magdaleniense Medio (13.600 BP -16.650 cal. BP-) se había aproximado a unos $6 \mathrm{~km}$ del litoral actual. La presencia de conchas, por lo general, es muy escasa hasta el Magdaleniense Superior o Final (Urtiaga D, Santa Catalina -BERGANZA et al. 2012, 2014-), periodo en el que se consolidan las pruebas de esta actividad, como consecuencia del acercamiento de la línea de costa a unos 2,1 km de distancia hacia el 11.200 BP (13.100 cal. $\mathrm{BP})$. Sin embargo, a pesar de no tener pruebas fehacientes, es inevitable sostener que esos recursos serían también explotados en periodos anteriores (hay Patella en el Musteriense de Amalda, etc.), y que los asentamientos solutrenses y magdalenienses más próximos a la antigua línea de costa irían quedando progresivamente sumergidos a lo largo del Tardiglaciar. Sólo a partir de estas fechas podría compensar el marisqueo efectuado desde yacimientos actualmente casi costeros, aunque con anterioridad sí que pudo darse el transporte de partes exclusivamente carnosas de grandes mamíferos marinos -que sí recompensarían el esfuerzo-, pero cuyos restos no han llegado hasta nosotros, salvo que además de la carne se transportase alguna parte del esqueleto para su transformación en instrumentos u objetos de arte (Isturitz, Mas d'Azil, etc.), o con otra finalidad desconocida (Santa Catalina).

Por lo expuesto hasta el momento, proponemos que durante los meses más desapacibles sería la zona correspondiente a la actual plataforma continental la más intensamente ocupada, internándose hacia el interior del territorio, siguiendo los diferentes cursos fluviales, durante los meses más benignos, y estableciéndose temporalmente al aire libre y en distintas cavidades, llegando a alcanzar los afloramientos del interior donde se abastecerían de sílex... Este recorrido teórico lo compaginarían con el aprovechamiento de recursos vegetales (la maduración de los frutos sería más tardía en zonas más interiores al ir aumentando la altura del territorio, etc.), pero el desconocimiento de yacimientos interiores, correspondientes a altos en dicho recorrido, dificulta profundizar o concretar más éste y otros aspectos. Además, algunos de estos grupos accederían también a la vertiente norpirenaica donde son frecuentes las ocupaciones durante las estaciones más desapacibles.

En resumen, la cueva de Praileaitz I se localiza próxima a la actual desembocadura del Deba y casi en el borde de las masas calizas albienses de la formación Erlo. Al inicio del Tardiglaciar, la línea de costa se situaba a unos $12 \mathrm{~km}$, y entre ella y la cavidad se extendía un territorio de relieve suave, donde el 97,8\% tenía una pendiente inferior al 10\%, frente al 3,29\% que representaría en su entorno actual. Esa banda sería el emplazamiento idóneo para establecer sus campamentos base, así como la zona de tránsito de las poblaciones humanas y de animales de este a oeste, y viceversa, accediendo desde ella hacía el interior siguiendo el curso de los ríos. A lo largo del Tardiglaciar, como consecuencia de la elevación del nivel del mar, se fue constriñendo el territorio, lo que provocó al final del pleistoceno una notable concentración de yacimientos, identificados por ahora únicamente en las zonas calizas costeras.

Conscientes de la dificultad de probar irrefutablemente la relación existente entre los habitantes de Praileaitz I y los yacimientos del entorno más próximo, así como la manera en que se movían (sin paradas o realizando otras actividades, etc.), podemos señalar que entre las cavidades excavadas hay algunas que frecuentaron casi con seguridad, como es el caso de las más próximas, situadas a menos de media hora (Ermittia, Langatxo), o aquellas otras ubicadas a menos de 2 horas y que muestran cronologías coetáneas (Urtiaga, Agarre o Aizkoltxo). Es probable que acudiesen a otras situadas a mayor distancia, (Ekain, Amalda, Erralla, etc.), pero es difícil suponer que lo hicieran directamente, enmarcándose probablemente en otro tipo de movimientos estacionales. Algunos de éstos se hallan en valles de afluentes del río principal (Urola) por lo que se internarían en ellos para acceder a biotopos muy concretos donde abundarían ciertas especies cinegéticas (sarrio en Amalda, cabra en Erralla, etc.).

\section{4.- AGRADECIMIENTOS}

El presente trabajo se enmarca dentro del Grupo de Investigación IT-622-13 del Sistema Universitario Vasco (UPV-EHU).

\section{5.- BIBLIOGRAFÍA}

\section{AGUIRRE RUIZ DE GOPEGUI, M.}

2000 El yacimiento paleolítico de Antoliñako Koba (Gautegiz-Arteaga, Bizkaia): secuencia estratigráfica y dinámica industrial. Avance de las campañas excavación 1995-2000. Illunzar 4, 38-81.

AGUIRRE RUIZ DE GOPEGUI, M., LÓPEZ QUINTANA, J. C., SÁENZ DE BURUAGA, A.

2000 Medio ambiente, industrias y poblamiento prehistórico en Urdaibai. Illunzar 4, 13-38.

ALTUNA, J.

1990 La caza de herbívoros durante el Paleolítico y Mesolítico del País Vasco. Munibe Antropologia-Arkeologia 42, 229 240.

ALTUNA, J., MERINO, J.M ${ }^{a}$

1984 El yacimiento prehistórico de la Cueva de Ekain (Deba, Guipúzcoa). Sociedad de Estudios Vascos. San Sebastián. 
ALTUNA, J., BALDEÓN, A., MARIEZKKURRENA, K.

1985 Cazadores magdalenienses en la Cueva de Erralla (Cestona, País Vasco). Munibe Antropologia-Arkeologia 37.

1990 La Cueva de Amalda (Zestoa, País Vasco). Ocupaciones paleolíticas y postpaleolíticas. Sociedad de Estudios Vascos. San Sebastián.

ALLEY, R. B.

2000 The Younger Dryas cold interval as viewed from central Greenland. Quaternary Science Reviews 19, 213-226.

BARD, E., ARNOLD, M., FAIRBANKS, R.G., HAMELIN, B.

$1993{ }^{230} \mathrm{Th}$ and ${ }^{14} \mathrm{C}$ ages obtained by mass spectrometry on corals. Radiocarbon 35, 191-199.

BARD, E., HAMELIN, B., DELANGHE-SABATIER, D.

2010 Deglacial Meltwater Pulse 1B and Younger Dryas Sea Levels revisited with Boreholes at Tahiti. Science 327, 12351237.

BASSET, E.S., MILNE, G.A., MITROVICA, J.X., CLARK, P.U.

2005 Ice Sheet and Solid Earth Influences on Far-Field SeaLevel Histories. Science 309, 925-928.

BERGANZA, E.

2005 El tránsito del Tardiglaciar al Holoceno en el País Vasco. Munibe Antropologia-Arkeologia 57, 249-258.

BERGANZA, E., ARRIBAS, J.L., CASTAÑOS, P., ELORZA, M., GONZÁLEZ, J.E., IBAÑEZ, J.I., IRIARTE, M.J., MORALES, A., PEMÁN, E., ROSALES, T., ROSELLÓ, E., RUIZ IDARRAGA, R., URIZ, A., UZQUIANO, P., VÁSQUEZ., V., ZAPATA, L.

2012 La transición tardiglaciar en la costa oriental de Bizkaia: el yacimiento de Santa Catalina. Resultados preliminares, en ARIAS, P., CORCHON, M.S., MENENDEZ, M., RODRIGUEZ, J.A. (Eds.) El Paleolítico Superior Cantábrico. Actas de la $1^{a}$ Mesa Redonda (26-28 de abril de 2007). San Román de Candamo (Asturias).

BERGANZA-GOCHI, E., ARRIBAS PASTOR, J.L.

2014 La Cueva de Santa Catalina (Lekeitio): La intervención arqueológica. Restos vegetales, animales y humanos. (Kobie -Bizkaiko arkeologi Indusketak- BAl, 4.)

BLANCHON, P.

2011 Meltwater Pulses, en HOPLEY, D. (Ed.). Encyclopedia of Modern Coral Reefs: Structure, form and process. 683690. Springer-Verlag Earth.

CLARK, P.

2002 The role of the thermohaline circulation in abrupt climate change. Nature 415, 863-869.

CLARK, P.U., MCCABE, A.M., MIX, A.C., WEAVERET, A.J.

2004 Rapid rise of sea level 19,000 years ago and its global implications. Science 304, 1141-1144.

CLARK, J., MCCABE, A.M., SCHNABEL, C., CLARK, P.U., FREEMAN, S., MADEN, C., XU, S.

2009 10Be chronology of the last deglaciation of County Donegal, northwestern Ireland. Boreas 38, 111-118.
CLARK, J., DYKE, A., SHAKUN, J., CARLSON, J., CLARK, J., WOHLFARTH, B., MITROVICA, J., HOSTETLER, S., MARSHALL MCCABE, A.

2009 The Last Glacial Maximum. Science 325, 710-714.

EASTMAN, J. R.

1989 Pushbroom Algoritms for Calculating Distances in Raster Grid. Procedings AUTOCARTO 9, 288-297.

EDESO, J. M.

1990 Geomorfología fluvial y litoral del extremo oriental de Gipuzkoa (País Vasco). Tesis doctoral. Universidad de Zaragoza.

EDESO, J. M., MUJIKA, J. A.

2005 El entorno de Zarautz durante el Cuaternario. Evolución paisajistica, ambiental y humana. Museo de Arte e Historia de Zarautz. Zarautz.

EDWARDS, R.L.

1993 A large dropp in atmospheric 14C/12C and reduced melting in the Younger Dryas, documented whit $230^{\text {th }}$ ages of corals. Science 260, 962-968.

FAIRBANKS, R.G., FLEMING, K., JOHNSTON, P., ZWARTZ, D. YOKOYAMA, Y., LAMBECK, K., CHAPPELL, J.

1998 Refining the eustatic sea-level curve since the Last Glacial Maximum using far- and intermediate-field sites. Earth and Planetary Science Letters 163 (1-4), 327-342.

1989 A 17000 year glacio-eustatic sea level record: influence of glacial melting rates on the Younger Dryas event and deep-ocean circulation. Nature 342, 637-642.

GANSKOPP, D

2000 Least-effort pathways: A GIS analysis of livestock trails in rugged terrain. Applied Animal Behavior Science 68(2), 179-190.

GONZÁLEZ MORALES, M. R.

1982 El Asturiense y otras culturas locales. La Explotación de las áreas litorales de la Región Cantábrica en los tiempos epipaleolíticos. Centro de Investigación y Museo de Altamira 7. Ministerio de Cultura. Madrid.

GORNITZ, V.

2013 Rising Seas: Past, Present, and Future. Columbia University Press. New York.

GRIP MEMBERS

1993 Climate instability during the last interglacial period recorded Ain the GRIP ice core. Nature 364, 203-207.

GROOTES, P.M., STUIVER, M., WHITE, J.W.C., JOHSEN, S., JOUZEL, J.

1993 Comparison of Oxygen Isotope Records from GISP2 and GRIP Greenland Ice Core. Nature 366, 552-554. 
GUTIÉRREZ ZUGASTI, F. I.

2009 La explotación de moluscos y otros recursos litorales en la región Cantábrica durante el Pleistoceno Final y el Holoceno Inicial. Universidad de Cantabria. Santander.

HANEBUTH, J,

2000 Rapid flooding of the Sunda Shelf: a late glacial sea-level record. Science 288, 1033-1035.

IRIARTE, M.J.

2009 Evolución del bosque durante el Pleistoceno Superior y el Holoceno en Bizkaia. Un estado de la cuestión provisional. Kobie XXVIII, 9-24.

2010 El entorno vegetal del megalitismo en la encrucijada vasca. Munibe 32, 462-471.

LAVILLE, H., RIGAUD, J.P., SACKEIT, J.

1980 Rock shelters of the Perigord. Geological stratigraphy and Archaeological succesion. Academic Press. New York.

LISIECKI, L., RAYMO, M

2005 A Pliocene-Pleistocene stock of 57 globally distributed benthic $\delta^{18} \mathrm{O}$ records. Paleoceanography 20, 1-17.

LIU, J.P., MILLIMAN, J. D., GAO, S., CHENG, P.

2004 Holocene development of the Yellow River's subaqueous delta, North Yellow Sea. Marine Geology 209(1-4), 45-67.

LOPETEGI GALARRAGA, A., EDESO-FITO, J.M., MUJIKA-ALUSTIZA, J.A

2012 XII Reunión Nacional de Geomorfología. Niveles transgresivos recientes entre las desembocaduras del Bidasoa y del Oiartzun-bahía de Pasajes (Gipuzkoa). Santander: 331-334.

LÓPEZ QUINTANA, J. C. ET AL.

2011 La cueva de Santimamiñe: revisión y actualización (20042006). (Kobie -Bizkaiko arkeologi Indusketak- BAl, 1.$)$

MEESE, D., ALLEY, R., GOW, T., GROOTES, P. M., MAYESWSKI, P., RAM, M., TAYLOR, K., WADDINGTON, E., ZIELINSKI, G.

1994 Preliminary depth-age scale of the GISP2 ice core. CRREL Special Report, 94(1). Cold Regions Research and Engineering Laboratory 66. Hanover. New Hamsphire.

MENÉNDEZ, M., JIMENO, A., FERNÁNDEZ, V.M.

1997 Diccionario de Prehistoria. Alianza Editorial. Madrid.
OCHOA GUTIÉRREZ, L.H.

2007 Determinación de un modelo de velocidad de desplazamiento en campo para trabajos de exploración Geofisica. Trabajo de grado para optar al título de Magister en Geomática. Universidad Nacional de Colombia, Facultad de Agronomía, Bogotá.

PEÑALVER, X., MUJIKA, J.A

2005 La cuestión de las azagayas de base hendida magdalenienses en la Cornisa Cantábrica. Veleia 22, 9-21.

RIVERA ARRIZABALAGA, A.

2004 Paleoclimatología y cronología del Würm reciente: un intento de síntesis. Zephyrus 57, 27-53.

SÁNCHEZ GOÑI, M. F., D’ERRICO, F.

2005 La historia de la vegetación y el clima del último ciclo climático (OIS5-OIS1, 140.000-10.000 años BP) en la Península lbérica y su posible impacto sobre los grupos paleolíticos, en MONTES BARQUIN, R. \& LASHERAS, J.A. (eds.) Neandertales cantábricos, estado de la cuestión. 115-129. Museo Nacional y Centro de Investigación de Altamira. (Monografías; 20).

SHACKLETON, N.J., OPDYKE, N.D.

1973 Oxigen isotope and paleomagnetic stratigraphy of Equatorial Pacific Core V28-238: Oxigen isotope temperatures and ice volumes on $10^{5}$ year and $10^{6}$ year scale. Quaternary Research 3, 39-55.

SOWERS, T., BENDER, M., LABEYRIE, L., MARTINSON, D., JOUZEL, J., RAYNAUD, D., PICHON, J.J., KOROTKEVICH, A.

1993 A 135000 year Vostok-Specmap common temporal framework. Paleoceanography 8, 737-766.

TARRIÑO VINAGRE, A.

2006 El sílex en la cuenca vasco-cantábrica y Pirineo navarro: caracterización y su aprovechamiento en la Prehistoria. Ministerio de Cultura. Madrid.

TTRL. TRANSPORT RESEARCH LABORATORY

1978 Guidelines for providing for journeys on foot. 163. Londres.

URIARTE, A.

2003 Historia del Clima de la Tierra. Servicio Central de Publicaciones de Gobierno Vasco. Vitoria-Gasteiz.

WEAVER, A. J.

2003 Meltwater pulse $1^{\text {a }}$ from Antartica as a trigger of the Bölling-Allerod warm interval. Science 299, 1709-1713. 
